\title{
Statistical and Economic Significance of Stock Return Predictability: A Mean-Variance Analysis
}

\author{
Steven X. Wei and Chu Zhang*
}

This version: May 2000

\begin{abstract}
In this paper, we use mean-variance analysis to investigate the statistical and economic significance of stock return predictability as documented in Fama and French (1992). We ask if investors who form mean-variance efficient portfolios conditioned on the predictive variables can earn higher expected returns and higher expected utility than those who optimize unconditionally. The result shows that, by and large, they cannot. We examine various reasons for the lack of economic gains from return predictability and conclude that, while the in-sample relation between returns and predetermined firm-specific variables is strong in terms of the $t$-statistics, it is not stable enough to produce better out-of-sample predictions.
\end{abstract}

JEL Classification: G12

Keywords: Return predictability; Firm-specific variables; Mean-variance analysis; Out-of-sample prediction; Certainty equivalent of expected utility

${ }^{*}$ The Hong Kong University of Science and Technology (HKUST). Address correspondence to Chu Zhang, Department of Finance, HKUST, Clear Water Bay, Kowloon, Hong Kong, Phone: (852)-23587684; E-mail: czhang@ust.hk. We would like to thank K.C. Chan, Jin-chuan Duan, John Wei and seminar participants at HKUST and City University of Hong Kong for their helpful comments and suggestions. The financial support from the RGC Competitive Earmarked Research Grant HKUST6016/99H is gratefully acknowledged. All remaining errors are ours. 


\section{Introduction}

The predictability of stock returns has always been at the center of asset pricing research. While return predictability itself has become more and more accepted, its interpretation has remained controversial. Return predictability is demonstrated by using two types of variables. One is marketwide variables. Examples include the short-term interest rate, the aggregate dividend-price ratio, and the default premium. The other is firm-specific variables. Fama and French (1992) conduct an extensive comparison among many firmspecific variables that have been considered in the earlier literature. They conclude that firm size and book-to-market ratio are the two most important variables in explaining cross sectional differences in expected stock returns, while the market beta based on the Capital Asset Pricing Model (CAPM) is not priced. Fama and French's finding has caused some debate among researchers because it poses a challenge to the wellknown notion that only systematic risk measured by the covariances (or betas) between the returns and marketwide factors should be priced and other firm-specific variables should not play any role in forming expected returns because firm-specific risks can be diversified away.

To examine further the return predictability issue, Fama and French (1993) form two factor-mimicking portfolios based on size and book-to-market ratio, test the model with these two factors along with the market portfolio, and find the model is not rejected. Fama and French (1996) further report that the two factor-mimicking portfolios can explain most asset pricing anomalies. They interpret the predictive power of firm-specific variables as proxies for the covariation with some unobserved systematic factors. Such a view, however, is not shared by all researchers. Lakonishok, Shleifer and Vishny (1994) and La Porta, Lakonishok, Shleifer and Vishny (1997), for example, contend that the predictive power of a firm's characteristics comes from the irrational behavior of the investors who overreact to the past performance of the firms and drive the stock prices away from their fundamental values. On the methodological front, Ferson (1996) 
cautions against the use of firm-characteristics-sorted portfolios as factors to explain return predictability, because of the potential self-serving nature of the portfolios. Ferson et al (1998) provide a simulated example to illustrate the possibility. The issue seems far from being settled.

Given that the task of identifying economic factors is difficult, we take a different approach to the issue in this paper. We conduct an experiment to investigate the economic significance of return predictability by measuring the gains in expected returns and in expected utility for an investor who uses the information in the firm-specific variables, compared to an investor who does not, in a mean-variance optimization framework. The examination of the gain in expected utility sidesteps the problem of identifying true factors and, therefore, makes a direct attack on the problem of finding out if return predictability is consistent with the equilibrium in which investors make optimal investment decisions.

Investigation of the gain in expected utility has been performed by many researchers in financial studies. In a paper unrelated to stock return predictability, McCulloch and Rossi (1990) propose an economic measure of mis-specification of an asset pricing model. In their approach, an asset pricing model puts a possibly incorrect restriction on an otherwise unrestricted model of the data generating process for asset returns. An investor belonging to a certain class of utility functions makes her portfolio decisions with or without the restriction and generates two different levels of the expected utility. The difference in the two levels of the expected utility, or the certainty equivalent in monetary terms, serves the purpose of an economic measure of the loss due to the incorrect asset pricing model. While their work is unrelated to the predictability of stock returns, the formulation of economic significance is very useful for our purpose. In an analytical model, Kandel and Stambaugh (1996) address the issue of translating statistical significance of the stock return predictability into its economic significance. They show that although the predictive regression relationship may be weak, it can exert a substantial 
influence on the investor's portfolio decision, even when the investor's prior beliefs are weighted against return predictability. Their results reinforce the notion that, in practice, investors may make their portfolio decisions based on insignificant statistics, as long as the predictability is economically significant. Pesaran and Timmermann (1995) also perform an empirical study on economic significance of return predictability of marketwide variables. Both the Kandel-Stambaugh study and the Pesaran-Timmermann study focus on the case of one risky asset and one riskfree asset. The issue of predictive power of firm-specific variables in explaining cross-sectional differences in stock returns is not the focus of their studies.

We examine the monthly returns on several sets of portfolios from 1963 to 1998 and find the following. The portfolio return can be predicted in the usual sense of significant $t$-ratios of the slope coefficients of firm-specific variables in predictive regressions. Exploiting the information in the firm-specific variables to form mean-variance optimal portfolios may generate significantly higher expected returns, but not higher expected utility. In fact, in many cases, the investors who use the information contained in the firm-specific variables end up doing worse than the investors who do not use the information. We then examine the reasons for the lack of economic gains from the return predictability. It is found that the optimal portfolio based on the firm-specific variables is indeed different from the one that does not depend on the information, so the information is not immaterial. However, the relationship between stock returns and firm-specific variables is not stable enough to be useful. Estimation errors and nonnormality of returns may also contribute to the lack of economic gains, but they are not the main reasons. The result presented in this paper has important implications on the consistency between return predictability and asset pricing rationality.

The rest of the paper is organized as follows. Section 2 presents the issue in the meanvariance framework and lays out the plan for the experiment. Section 3 first describes the data and portfolio formation methods and then presents the main result that return 
predictability does not lead to economic gains. Section 4 examines various reasons for the lack of economic gains from return predictability. The concluding section discusses the implications of the results.

\section{The Design of the Experiment}

\subsection{The Statistical Model of Investors}

Suppose there are $N$ assets whose rates of return from period $t$ to $t+1$ in excess of the riskfree rate are normally distributed and are denoted as $r_{t+1}$. The excess returns are assumed to be a stationary process.

There are two classes of investors. One class of investors believes that the return $r_{t+1}$ can be predicted using certain firm-specific variables, while the other class of investors does not believe in return predictability. Nonbelievers may either think the returns are not predictable at all or they may think the returns can be predicted in a way that is consistent with the equilibrium of the risk-return trade-off. In either case, nonbelievers do not act on the time $t$ firm-specific information that is not already contained in asset prices. Let the nonbelievers' information set at $t$ be $\mathcal{F}_{t}^{n}=\left\{r_{\tau}, r_{0 \tau}, 1 \leq \tau \leq t\right\}$ and the believers' information set at $t$ be $\mathcal{F}_{t}^{b}=\left\{\left(r_{\tau}, r_{0 \tau}, X_{\tau}\right), 1 \leq \tau \leq t\right\}$ where $r_{0 \tau}$ is the riskfree rate known at $\tau$ for the period $\tau$ to $\tau+1$, and $X_{\tau}$ is a $N \times M$ matrix of firm-specific variables at $\tau$, assumed to be stationary processes.

Suppose the returns are generated by

$$
r_{t+1}=\alpha+X_{t} \theta+\varepsilon_{t+1}
$$

where $\alpha$ is an $N$-vector and $\theta$ is an $M$-vector. Denote $\operatorname{Var}\left(\varepsilon_{t+1}\right)=\operatorname{Var}\left(r_{t+1} \mid X_{t}, \alpha, \theta\right) \equiv$ $\Omega$. $\alpha, \theta$, and $\Omega$ are all unknown parameters. A believer uses the correct model while a nonbeliever uses a model unconditioned on $X_{t}: r_{t+1}=\nu+u_{t+1}$ with $\operatorname{Var}\left(u_{t+1}\right)=$ $\operatorname{Var}\left(r_{t+1} \mid \nu\right) \equiv \Psi>\Omega$. 
At time $t$, a nonbeliever will estimate $\nu$ and $\Psi$ by

$$
\begin{aligned}
\hat{\nu}_{t}^{n} & =\frac{1}{t} \sum_{\tau=1}^{t} r_{\tau}, \\
\hat{\Psi}_{t} & =\frac{1}{t} \sum_{\tau=1}^{t}\left(r_{\tau}-\hat{\nu}_{t}^{n}\right)\left(r_{\tau}-\hat{\nu}_{t}^{n}\right)^{\prime} .
\end{aligned}
$$

The nonbeliever estimates the conditional mean of the next period return $E\left(r_{t+1} \mid \mathcal{F}_{t}^{n}, \alpha\right)=$ $\alpha$ by $E\left(r_{t+1} \mid \mathcal{F}_{t}^{n}\right)=\nu_{t}^{n}$. If he knew the value of $\Psi$, he would estimate the variance of the next period return with respect to $\nu_{t}^{n}$ by,

$$
\begin{aligned}
\Psi_{t} & =E\left[\left(r_{t+1}-\hat{\nu}_{t}^{n}\right)\left(r_{t+1}-\hat{\nu}_{t}^{n}\right)^{\prime} \mid \mathcal{F}_{t}^{n}, \Psi\right] \\
& =E\left[\left[\left(r_{t+1}-\nu\right)+\left(\nu-\nu_{t}^{n}\right)\right]\left[\left(r_{t+1}-\nu\right)+\left(\nu-\nu_{t}^{n}\right)\right]^{\prime} \mid \mathcal{F}_{t}^{n}, \Psi\right] \\
& =\Psi+\frac{1}{t} \Psi=\frac{t+1}{t} \Psi .
\end{aligned}
$$

But since the nonbeliever does not know $\Psi$, he estimates $\Psi_{t}$ by

$$
V_{t}^{n} \equiv[(t+1) / t] \hat{\Psi}_{t}
$$

Let the $t$-vector of ones be denoted as $1_{t}$, the $t \times t$ identity matrix be denoted as $I_{t}$, the returns and the firm-specific variables be stacked as $\vec{r}_{t}=\left(r_{1}^{\prime}, r_{2}^{\prime}, \cdots, r_{t}^{\prime}\right)^{\prime}$ and $\vec{X}_{t-1}=$ $\left(X_{0}^{\prime}, X_{1}^{\prime}, \cdots, X_{t-1}^{\prime}\right)^{\prime}$. At time $t$, a believer estimates $(\alpha, \theta)$ by solving the generalized least square problem,

$$
\left(\hat{\alpha}_{t}, \hat{\theta}_{t}\right)=\arg \min _{\alpha, \theta}\left(\vec{r}_{t}-1_{t} \otimes \alpha-\vec{X}_{t-1} \theta\right)^{\prime}\left(I_{t} \otimes \hat{\Omega}_{t-1}\right)^{-1}\left(\vec{r}_{t}-1_{t} \otimes \alpha-\vec{X}_{t-1} \theta\right),
$$

where $\hat{\Omega}_{t-1}$ is the estimate of $\Omega$ at $t-1$. This estimate of $\Omega$ is then updated at $t$ by

$$
\hat{\Omega}_{t}=\frac{1}{t} \sum_{\tau=1}^{t}\left(r_{\tau}-\hat{\alpha}_{t}-X_{\tau-1} \hat{\theta}_{t}\right)\left(r_{\tau}-\hat{\alpha}_{t}-X_{\tau-1} \hat{\theta}_{t}\right)^{\prime}
$$

The believer then estimates the expected value of the next period return $\nu_{t}^{b} \equiv \alpha+X_{t} \theta$ conditioned on true parameters by $\hat{\nu}_{t}^{b} \equiv \hat{\alpha}_{t}+X_{t} \hat{\theta}_{t}$. If the believer knew the value of $\Omega$ exactly, he would estimate the variance of $r_{t+1}$ with respect to $\hat{\nu}_{t}^{b}$ as,

$$
\begin{aligned}
\Omega_{t} & \equiv E\left[\left(r_{t+1}-\hat{\nu}_{t}^{b}\right)\left(r_{t+1}-\hat{\nu}_{t}^{b}\right)^{\prime} \mid \mathcal{F}_{t}^{b}, \Omega\right] \\
& =E\left[\left[\left(r_{t+1}-\nu_{t}^{b}\right)+\left(\nu_{t}^{b}-\hat{\nu}_{t}^{b}\right)\right]\left[\left(r_{t+1}-\nu_{t}^{b}\right)+\left(\nu_{t}^{b}-\hat{\nu}_{t}^{b}\right)\right]^{\prime} \mid \mathcal{F}_{t}^{b}, \Omega\right] \\
& =\Omega+\left(I_{n}, X_{t}\right)\left[\left(1_{t} \otimes \hat{\alpha}_{t}+\vec{X}_{t} \hat{\theta}_{t}\right)^{\prime}\left(I_{t} \otimes \hat{\Omega}_{t}\right)^{-1}\left(1_{t} \otimes \hat{\alpha}_{t}+\vec{X}_{t} \hat{\theta}_{t}\right)\right]^{-1}\left(I_{n}, X_{t}\right)^{\prime}
\end{aligned}
$$


Since he does not know $\Omega$ exactly, he then estimates $\Omega_{t}$ by

$$
V_{t}^{b} \equiv \hat{\Omega}_{t}+\left(I_{n}, X_{t}\right)\left[\left(1_{t} \otimes \hat{\alpha}_{t}+\vec{X}_{t} \hat{\theta}_{t}\right)^{\prime}\left(I_{t} \otimes \hat{\Omega}_{t}\right)^{-1}\left(1_{t} \otimes \hat{\alpha}_{t}+\vec{X}_{t} \hat{\theta}_{t}\right)\right]^{-1}\left(I_{n}, X_{t}\right)^{\prime}
$$

Suppose at each $t$, the believer estimates the mean and the variance of the returns $r_{t+1}$ conditioned on his information set, forms his optimal portfolio, invests one dollar in the portfolio, and liquidates the portfolio at $t+1$. Similarly, the nonbeliever does the same thing based on his information. In such an experiment, two time series of returns will be generated that can be used to estimate the economic gains from the return predictability under the stationarity assumption.

Before we move to the portfolio problem, we note that the believer's model (??) differs from that in Fama and French (1992). In the Fama-French regression estimated by the cross-sectional regression method, the cross-sectional difference in expected return comes only from the difference in the firm-specific variables. Here, we consider the predictive power of the firm-specific variable in addition to the information contained in the past returns. The expected excess returns across assets can be different even if the firmspecific variables have no predictive power because the elements of $\alpha=\left(\alpha_{1}, \alpha_{2}, \cdots, \alpha_{N}\right)^{\prime}$ can be different. The Fama-French model is more restrictive than the one here in that it restricts $\alpha_{1}=\cdots=\alpha_{N}$. Without such a constraint, the believer's model here nests the nonbeliever's as it should because the information set of the believer includes that of the nonbeliever. In principle, the believer will not fare worse than the nonbeliever in making investment decisions.

\subsection{The Portfolio Decisions}

To take advantage of the simplicity in portfolio decisions under normality, we assume that returns are normally distributed conditioned on the parameter estimates $\left(\nu_{t}^{n}, V_{t}^{n}\right)$ and $\left(\nu_{t}^{b}, V_{t}^{b}\right)$ and, therefore, the investors are mean-variance optimizers. In doing so, the estimation error in $\nu_{t}^{n}$ and $\nu_{t}^{b}$ are taken into consideration, while the estimation error 
in $V_{t}^{n}$ and $V_{t}^{b}$ are not. A full-blown Bayesian analysis can overcome this shortcoming, but that approach is not taken here because the closed form solution for predictive distribution does not exist and numerical solutions are not computationally suitable for our analysis. ${ }^{1}$

The investors are assumed to have a constant absolute risk aversion (CARA) utility function of the form $U(\tilde{w})=-e^{-A \tilde{w}}$ where $\tilde{w}$ is the next period's wealth, and $A$ is the absolute risk aversion coefficient. For each dollar of after-consumption current wealth normalized to equal one, let $\xi_{t}^{n}=\left(\xi_{1 t}^{n}, \cdots, \xi_{N t}^{n}\right)^{\prime}$ be the dollar amount the nonbeliever invests in risky assets, and let $1-1_{N}^{\prime} \xi_{t}^{n}$ be the amount invested in the riskfree asset. Similarly, the portfolio of risky assets held by the believer is denoted as $\xi_{t}^{b}$. Under the CARA utility function, the optimal portfolios by the nonbeliever and the believer, conditioned on their estimates of the parameters, are

$$
\begin{aligned}
\xi_{t}^{n} & =\frac{1}{A}\left(V_{t}^{n}\right)^{-1} \nu_{t}^{n}, \\
\xi_{t}^{b} & =\frac{1}{A}\left(V_{t}^{b}\right)^{-1} \nu_{t}^{b},
\end{aligned}
$$

respectively. Obviously, the smaller the risk aversion parameter, the more aggressively the investor trades.

\subsection{Economic Significance of Return Predictability}

There are several situations in which statistically significant predictability (i.e., a significant $\theta$ ) may not translate to economically significant predictability. First, statistical significance per se does not guarantee significant economic gains. It is possible that economic gains are negligible from statistically significant predictability. Second, the predictive power of a firm-specific variable may be consistent with the risk-return relationship. For example, small stocks tend to have higher expected returns, but they also have higher variance in the return. The predictive power of the size poses a challenge to the CAPM, but it may still be consistent with other multifactor pricing models.

\footnotetext{
${ }^{1}$ This shortcoming will be partially dealt with in Section 4.
} 
Third, the uncertainty about parameters and about model specification may cause suboptimal portfolio decisions that will reduce, or eliminate, the economic gains from return predictability.

Two quantities will be relevant to our primary interest in the economic gains of return predictability. One is the difference between the expected return on the optimal portfolio of the believer and that of the nonbeliever,

$$
E\left[r_{t+1}^{\prime}\left(\xi_{t}^{b}-\xi_{t}^{n}\right)\right]
$$

The other is the difference between the certainty equivalent returns of expected utility, or certainty equivalents for short, for the believer and the nonbeliever,

$$
C_{b}-C_{n},
$$

where the certainty equivalent, $C_{j}$ for $j=b, n$, of the CARA utility function is the solution to the following equation,

$$
-e^{-A C_{j}}=E\left[-e^{-A\left(1+r_{0 t}+r_{t+1}^{\prime} \xi_{t}^{j}\right)}\right], \quad j=b, n .
$$

The certainty equivalent is a risk-adjusted expected return. This is more obvious under the normality assumption and the CARA utility function for which

$$
C_{j}=1+E\left(r_{0 t}+r_{t+1}^{\prime} \xi_{t}^{j}\right)-\frac{A}{2} \operatorname{Var}\left(r_{0 t}+r_{t+1}^{\prime} \xi_{t}^{j}\right), \quad j=b, n .
$$

The expected return and the certainty equivalent can be estimated using their sample versions.

It should be kept in mind that in calculating the economic gains from trading on the information contained in the firm-specific variables, we ignore some real-world concerns such as short-selling restrictions and transaction costs. 


\section{Experimental Results on the Economic Gains from Return Predictability}

\subsection{The Data}

Since the implementation of the standard mean-variance theory requires calculation of the mean vector and variance matrix of the returns, it is typically performed on portfolios rather than on individual stocks, because of the dimension problem. In order to ensure sufficient variation in the predictive variable across portfolios, we form portfolios sorted by size and by book-to-market ratio. Since the result may quantitatively depend on how portfolios are formed, we form three different sets of portfolios, described below. ${ }^{2}$

We use the intersection of the data from Compustat and the Center for Research in Stock Prices (CRSP) for our study. Firms with book values in Compustat and returns in CRSP from 1963 to 1997 are included in our sample. ${ }^{3}$ The three sets of portfolios are labeled as SZ20, BM20 and SZBM25. SZ20 is the set of 20 portfolios sorted by size of individual firms, BM20 is the set of 20 portfolios sorted by book-to-market ratio of individual firms, and SZBM25 is the set of 25 portfolios sorted by both size and bookto-market ratio of individual firms with $5 \times 5$ independent sorting. We use the standard approach to determine the break points for sorting firms into portfolios. For 20 sizesorted portfolios, SZ20, we choose the break points as follows. For the end of June from 1963 to 1997, we sort all the firms traded on the New York Stock Exchange (NYSE) according to their sizes into 20 groups with equal numbers of firms in each group. The break points are then chosen for determining the portfolios in our sample for all firms traded on the NYSE, American Stock Exchange (AMEX) and NASDAQ. A portfolio changes its components at the end of June in next year. The similar procedure is used to form BM20 and SZBM25. The return on a portfolio is the simple average of the returns

\footnotetext{
${ }^{2}$ We also conduct similar analysis on randomly sampled individual firms. The result is qualitatively unchanged and, therefore, is not reported.

${ }^{3}$ We assume that the book value of a firm becomes available to investors three months after its fiscal year-end month.
} 
of the firms in the portfolio. The size of a portfolio, SZ, and the book-to-market ratio of a portfolio, BM, are calculated by first taking simple averages of the $\log ($ size) and the $\log$ (book-to-market ratio) of the firms within the portfolio, and then subtracting the mean across the portfolios.

Table 1 reports time series properties of the three sets of portfolios. We report the time series means and standard deviations of portfolio returns, sizes and book-to-market ratios for all portfolios. SZ20 is ordered from small-firm portfolios to large-firm portfolios. BM20 is ordered from low book-to-market portfolios to high book-to-market portfolios. For SZBM25 portfolios with two subscripts, the first one is its size from small to large and the second is its book-to-market from low to high. As expected, the size-sorted portfolios maintain large dispersion in their size, while book-to-market-sorted portfolios maintain large dispersion in their book-to-market ratios. The correlations between the size and the book-to-market ratio are substantial at the portfolio level for the portfolio sets SZ20 and BM20.

Table 1 here

For robustness check, we also use the two factor-mimicking portfolios, SMB and HML, introduced in Fama and French (1993). SMB is the return on the zero-cost portfolio that has long positions in firms whose sizes are above the median and short positions in firms whose sizes are below the median, both equally weighted. HML is the return on the zero-cost portfolio that has long positions in one-third of high book-tomarket firms and short positions in one-third of low book-to-market firms, both equally weighted. The time-series means and standard deviations of SMB and HML are reported in Panel C of Table 1. 


\subsection{Predictability}

Since portfolios may exhibit different patterns from individual firms, we first verify return predictability for the portfolios. Table 2 reports the Fama-French type of regression results on the three sets of portfolios, using the Fama-MacBeth methodology.

\section{Table 2 here}

Compared with the results in Fama and French (1992), we can see that the statistical significance of return predictability for portfolios is as strong as those for individual firms, when only one of the predictive variables is in the equation. When both variables are included, the estimated slope coefficients are slightly less significant than the singleregressor cases. This is so because, at the portfolio level, the two predictive variables are highly correlated as shown in Table 1 . The time-series averages of the $R^{2} \mathrm{~s}$ in the cross-sectional regressions range from 0.19 to 0.49 .

Table 3 reports the regression results for model (??) in which the intercept terms are allowed to be different across portfolios. In the upper panel for regressions using size as the regressor, the slope coefficient is insignificant (and positive) for SZ20, but significant and negative for BM20. The Wald test for the hypothesis $\theta=0$ conveys the same message. This is expected because, for size-sorted portfolios, the intercept term reflects the difference between the unconditional expected return across portfolios due to difference in their size, while the regressor $\mathrm{SZ}_{t}$ only picks up the effect of time variation in size in addition to the unconditional means. The book-to-market sorted portfolios have their intercepts reflecting the difference in unconditional mean due to book-to-market ratios, so the predictive power of the regressor $\mathrm{SZ}_{t}$ is still strong. This phenomenon also manifests itself in the results of the Wald test of the hypothesis $\alpha_{1}=\alpha_{2}=\cdots=\alpha_{N}$, denoted as $\alpha=\theta_{0} 1_{N}$ in the table. The case for SZBM25 portfolios lies in between SZ20 and BM20 in regard to the sign and significance of the slope coefficient and the p-values of the Wald tests. In the middle panel with $\mathrm{BM}_{t}$ as the regressor, the same phenomenon 
occurs. The slope coefficient for size-sorted portfolios is significant while that for bookto-market-sorted portfolios is less so. In the lower panel with both $\mathrm{SZ}_{t}$ and $\mathrm{BM}_{t}$ used as regressors, only the slope coefficients for BM20 portfolios are still quite significant with the correct signs. Others are less so, or even with a different sign compared with the original Fama-French regressions. The statistical significance of $\theta$ in these regressions is interesting by itself. It offers some information in addition to that from the Fama-French regressions.

\section{Table 3 here}

\subsection{Evidence of Economic Gains}

In Table 4, we present the main result of this paper, the two quantities described in the last section to measure the economic gains of return predictability. For each set of portfolios, we run a sequence of GLS regressions of returns on size and/or bookto-market for the period from 1963.07 to month $t$, where $t$ starts from 1970.12 and continues to 1998.11. At each $t$, we calculate $\nu_{t}^{n}, V_{t}^{n}, \nu_{t}^{b}, V_{t}^{b}$, and form optimal portfolios $\xi_{t}^{b}$ and $\xi_{t}^{n}$ for the believer and the nonbeliever respectively. From the two sequences of the realized optimal portfolio returns, $r_{0 t}+r_{t+1}^{\prime} \xi_{t}^{b}$ and $r_{0 t}+r_{t+1}^{\prime} \xi_{t}^{n}$, we calculate four quantities and report them in Table 4. The first is the time-series average of the difference in the two portfolio returns (column 2). This is the estimate of the difference in the expected returns between the believer and the nonbeliever. The second is the $t$-ratio of the estimate (column 3). The $t$-ratios are calculated using the Newey-West procedure with a lag equal to 3 to estimate the standard errors. The third quantity is the estimate of the difference in the certainty equivalents of expected utility for the believer and the nonbeliever, which depends on the risk aversion parameter $A$ and the investor's initial wealth. We follow McCulloch and Rossi (1990) by choosing $A=2,5,8,12$ and 15 (columns 4-8). These are the reasonable values that are consistent with the actual return patterns in U.S. history. More details can be found in McCulloch and Rossi 
(1990) and the references therein. The fourth quantity is the t-ratio (column 9) for the estimate of the difference in the certainty equivalents. The $t$-ratio turns out to be numerically insensitive to the choice of $A$. The numbers in Table 4 for the difference in returns and difference in certainty equivalent returns are expressed as dollar returns on a $\$ 100$ investment over a month.

\section{Table 4 here}

From the table, we see that the believer who uses the information contained in firmspecific variables does not fare much better than the nonbeliever who does not use the information. In almost all the cases the differences in expected returns and in certainty equivalents are not significantly different from zero. In many cases, the differences are even negative. This result is truly puzzling. It has important implications about the consistency between the return predictability and the asset pricing rationality. The next section explores the reasons that this happens.

\section{Why Doesn't Return Predictability Lead to Eco- nomic Gains?}

\subsection{Possible Reasons}

To understand why return predictability does not lead to economic gains, we consider several possible reasons in turn in this section.

The first possibility is that the information contained in the firm-specific variables is not material because the slope coefficients of the firm-specific variables in the crosssectional regressions are not very statistically significant, as we see from Table 3 . If that is the case, the optimal portfolios of the believer and the nonbeliever should not be very different and, as a result, the economic gains from return predictability will not be significantly different from zero. This possibility is examined in Section 4.2. 
The second reason for the believer to fare no better than the nonbeliever may come from estimation errors. Although both the believer's and the nonbeliever's models have estimation errors, the believer's model contains more parameters than that of the nonbeliever, and if the believer trades more aggressively than the nonbeliever, the estimation errors exert more influence on the believer than on the nonbeliever. These additional errors might be the source of the lack of economic gains from return predictability. Although it is difficult to handle the problem of estimation error, we will deal with the issue in Section 4.3 using simulation.

The third possible reason is the non-normality of the returns. In the design of the experiment as well as in the CAPM theory, returns are assumed to be normally distributed. ${ }^{4}$ The actual return distributions, however, may not be normal. The nonnormality will affect the experimental results because the optimality of the portfolio weights in (??)-(??) is based on normality. This issue will be taken up in Section 4.3 together with the discussion of the estimation errors.

The fourth possibility is the instability of the model parameters, which in turn implies the lack of out-of-sample predictability. Since the model of the nonbeliever is nested in the model of the believer, the in-sample fit of the believer's model will always be better than that of the nonbeliever. But if the model the believer uses is incorrect, or if the model parameters are unstable, then the one-step-ahead forecast based on the believer's model may not be better than that based on the nonbeliever's model. The optimality of the believer's portfolio in that case loses its meaning and the actual performance of the believer can be indistinguishable from, or even worse than, that of the nonbeliever. We examine this possibility in Section 4.4.

The fifth possibility regards the validity of mean-variance analysis. Suppose that the investment opportunity set changes stochastically as in Merton (1973) and that the dynamically optimal portfolio differs from the static mean-variance efficient portfolio.

\footnotetext{
${ }^{4}$ Without the normality assumption, the CAPM can be derived under a quadratic utility function, which is often criticized for its implication of increasing absolute risk aversion.
} 
In that case, the economic gains calculated in Table 4 do not capture the true economic gains. Verifying such a possibility is presumably difficult because of the difficulty in identifying the stochastic investment opportunity set. We will have some discussion about this in Section 4.4.

Since all of the above reasons may contribute to the lack of economic gains from return predictability, one may wonder what will happen if the believer uses some simple strategies that have long positions in small size and/or high book-to-market firms and have short positions in large size and/or low book-to-market firms with fixed portfolio weights. Such strategies have no additional estimation errors and do not depend on the mean-variance criterion. We perform such an analysis in Section 4.5 as a robustness check of our main result.

\subsection{An Examination of Portfolio Weights}

One possible reason for the difference in expected returns and in the certainty equivalents of the expected utility between the believer and the nonbeliever to be insignificantly different from zero is that the information contained in the firm-specific variables is not material. If that is the case, the optimal portfolio of the believer will not be very different from that of the nonbeliever. To see whether this is the actual reason, we look at the following measures,

$$
\begin{array}{rlrl}
D_{a, t} & =\frac{1}{N+1} \sum_{i=0}^{N}\left|\xi_{i t}^{b}-\xi_{i t}^{n}\right|, & D_{b, t} & =\frac{1}{N+1}\left(\sum_{i=0}^{N}\left(\xi_{i t}^{b}-\xi_{i t}^{n}\right)^{2}\right)^{1 / 2}, \\
D_{c, t} & =\frac{\sum_{i=0}^{N}\left|\xi_{i t}^{b}-\xi_{i t}^{n}\right|}{\left.\sum_{i=0}^{N} \mid \xi_{i t}^{n}\right) \mid}, & D_{d, t}=\left(\frac{\sum_{i=0}^{N}\left(\xi_{i t}^{b}-\xi_{i t}^{n}\right)^{2}}{\sum_{i=0}^{N}\left(\xi_{i t}^{n}\right)^{2}}\right)^{1 / 2}, \\
D_{e, t}=\frac{1}{N+1} \sum_{i=0}^{N}\left|\xi_{i t}^{b}-\xi_{i, t-1}^{b}\right|, & D_{f, t}=\frac{1}{N+1}\left(\sum_{i=0}^{N}\left(\xi_{i t}^{b}-\xi_{i, t-1}^{b}\right)^{2}\right)^{1 / 2}, \\
D_{g, t}=\frac{\sum_{i=0}^{N}\left|\xi_{i t}^{b}-\xi_{i, t-1}^{b}\right|}{\sum_{i=0}^{N}\left|\xi_{i t}^{n}-\xi_{i, t-1}^{n}\right|} & D_{h, t}=\left(\frac{\sum_{i=0}^{N}\left(\xi_{i t}^{b}-\xi_{i, t-1}^{b}\right)^{2}}{\sum_{i=0}^{N}\left(\xi_{i t}^{n}-\xi_{i, t-1}^{n}\right)^{2}}\right)^{1 / 2},
\end{array}
$$


where $\xi_{0 t}^{b}$ and $\xi_{0 t}^{n}$ are the weights in the riskfree asset at $t$ for the believer and nonbeliever, respectively. $D_{a, t}$ and $D_{b, t}$ measure the absolute difference between the two optimal portfolios using the usual $L_{1}$ and $L_{2}$ norms. $D_{c, t}$ and $D_{d, t}$ measure the relative difference between the two using the norm of the nonbeliever's portfolio as the base for comparison. $D_{e, t}$ and $D_{f, t}$ measure how variable the optimal portfolio weights of the believer are from time to time. $D_{g, t}$ and $D_{h, t}$ measure the variability over time of the believer's optimal portfolio weights relative to that of the nonbeliever. The time series averages are calculated and reported in Table 5. Among the eight measures, $D_{a, t}, D_{b, t}, D_{e, t}$ and $D_{f, t}$ are proportional to the reciprocal of the risk aversion parameter. The measures reported in Table 5 correspond to $A=8$.

\section{Table 5 here}

The numbers in Table 5 show that the two optimal portfolios are quite different. To be convinced, we need a benchmark. Consider a portfolio that is equally allocated in all $N+1$ assets. For $N=20$ and $N=25$, the equal weight should be 0.048 and 0.038 , respectively. Many numbers of the average $D_{a, t}$, which are the differences in the weights between believer and nonbeliever, exceed these two numbers by many times. This can happen because, without the short selling restriction, the absolute value of portfolio weights can be very large. By inspection, this is indeed the case for the portfolio of the believer. The averages of $D_{c, t}$ and $D_{d, t}$ reveal that a typical weight in the believer's portfolio is $11 \%$ to $68 \%$ different from that of the nonbeliever. The average of $D_{e, t}$ shows that, for almost all the cases, the month-to-month changes of the believer's portfolio are larger than the weight of the equally weighted portfolio. The averages of $D_{g, t}$ and $D_{h, t}$ show that in most cases the believer's portfolio is at least twice as changeable as that of the nonbeliever. Among the three sets of portfolios, the BM20 portfolios tend to have the largest variation between the believer and the nonbeliever.

The result in Table 5, therefore, excludes the possibility of too similar portfolio weights between the believer and the nonbeliever as the reason for insignificant economic 
gains from return predictability. The empirical result here is consistent with the analytical result of Kandel and Stambaugh (1996) who find that small return predictability causes large portfolio reactions.

\subsection{Parameter Uncertainty and Non-normality}

In this subsection we investigate other two possibilities of the poor performance of the believer. Is the poor performance due to the fact that the believer's model contains more parameters and the estimates of the parameters contain too large errors? Suppose the parameters are estimated accurately, is it possible that actual returns are non-normal, so that the optimal portfolio based on normality is in fact sub-optimal?

The first question cannot be perfectly answered without knowing the true values of the parameters. The second question cannot be answered either without knowing the true distribution that governs actual returns upon which we could construct the optimal portfolios, at least numerically. Given this, we approach the problems slightly differently by asking the following question. Suppose the estimated parameters of models contain no errors and suppose the distribution of returns is normal with means and variances equal to those estimated by the believer. What would be the economic gains from the return predictability in this situation? By design, the expected utility of the believer will be greater than that of the nonbeliever, which can be illustrated using simulation. But the magnitude of the difference can help us gauge the importance of the estimation errors and non-normality in accounting for the believer's failure with actual returns. If the difference in the simulation is large, then we can infer that estimation errors or non-normality may have contributed a great deal in the lack of economic gains reported in Table 4 using actual data. If the difference in the simulation is negligible, then we can infer that neither estimation errors nor non-normality is the main cause for the lack of economic gains.

The simulation is explained below for each set of portfolios and each set of firm- 
specific variables as regressors. For each month $t$ from 1970.12 to 1998.11 , we estimate the models for the believer and the nonbeliever using actual data from 1963.07 to $t$. The estimated parameters of the believer's model are then used to simulate normally distributed returns at $t+1$ with 1000 replications. Both the believer and the nonbeliever build their portfolios using their own estimates, which are based on actual data. Simulated returns are used to calculate economic gains only. The simulation generates 1000 pairs of time series of returns (1000 time-series of returns for the believer and 1000 timeseries of returns for the nonbeliever). Each pair of time series can be used to calculate a time-series average of the difference in returns, the time-series $t$-ratio of the difference, a certainty equivalent difference of expected utilities for a given $A$, and its associated time-series $t$-ratio, just like those in Table 4. The distributions of these quantities across 1000 replications are reported in Table 6 using percentiles. The numbers in the table for

the difference in returns and difference in certainty equivalents are expressed as dollar returns on a $\$ 100$ investment over a month.

\section{Table 6 here}

From the table, we can see that out of the 1000 replications, most of the estimates of the differences in returns and in certainty equivalents are positive. This is anticipated because the returns used for the calculation are drawn from the normal distribution with parameters equal to the believer's estimation. The results are mixed, however, across different portfolio sets and different predictive variables. The gains in terms of mean returns are nontrivial, especially for the portfolio set BM20. Recall that, for BM20 with $X_{t}=\mathrm{SZ}_{t}$, the $50 \%$ percentile of 0.40 means that the difference between $\$ 100$ invested in the believer's portfolio and $\$ 100$ invested in the nonbeliever's portfolio resulted in a time-series average dollar return of $\$ 0.40$ per month, or almost $5 \%$ per year. The $t$-ratio beside it shows that the gain is significantly different from zero. The gains in the certainty equivalents, though mostly positive, appear to be smaller on average than the mean returns, indicating the effect of larger variation caused by trading more 
aggressively on return predictability. For the portfolio set SZBM25, both the differences in mean returns and in certainty equivalents are meager.

In sum, the effect of estimation errors and non-normality on the lack of gains from return predictability is mixed. In some cases, they may be part of the reasons that hinder the believer to do better than the nonbeliever, but in other cases, they are not major reasons.

\subsection{Cross-sample Comparison and Out-of-sample Prediction}

If the portfolio weights of the believer differ much from those of the nonbeliever and estimation errors and non-normality do not necessarily contribute much to the lack of economic gains of the believer, then the stability of the model parameters is in doubt. This can be easily checked by cross-sample comparison and by calculating one-step-ahead prediction errors.

To examine whether the parameters $\left(\alpha, \theta_{1}, \theta_{2}\right)$ of the believer's model are stable, we can divide the whole sample period into two different samples and test the hypothesis that the parameters remain the same across the two samples. We consider two ways of dividing the sample. In the first, the entire sample is divided chronologically into two parts of equal length, 1963.07-1981.03 and 1981.04-1998.12. In the second, the sample is divided between odd-months (January, March, May, July, September and November) and even-months (February, April, June, August, October and December). In Table 7, we report results from the Wald tests, the likelihood ratio tests and the Lagrange multiplier tests of the hypothesis that the parameters remain the same across the two subsamples. The p-values in the brackets based on the asymptotic $\chi^{2}$ distributions indicate that the hypothesis is rejected at the 0.01 significance level in 12 out of 18 cases, and is rejected at the 0.1 level for almost all the cases.

Table 7 here 
We then consider the measures of one-step-ahead out-of-sample predictive power of the believer's model relative to the nonbeliever's model as follows,

$$
\begin{aligned}
R_{O L S, t}^{2} & =1-\frac{\left(r_{t+1}-\hat{\alpha}_{t}-X_{t} \hat{\theta}_{t}\right)^{\prime}\left(r_{t+1}-\hat{\alpha}_{t}-X_{t} \hat{\theta}_{t}\right)}{\left(r_{t+1}-\hat{\nu}_{t}^{n}\right)^{\prime}\left(r_{t+1}-\hat{\nu}_{t}^{n}\right)}, \\
R_{G L S, t}^{2}\left(V_{t}^{b}\right) & =1-\frac{\left(r_{t+1}-\hat{\alpha}_{t}-X_{t} \hat{\theta}_{t}\right)^{\prime}\left(V_{t}^{b}\right)^{-1}\left(r_{t+1}-\hat{\alpha}_{t}-X_{t} \hat{\theta}_{t}\right)}{\left(r_{t+1}-\hat{\nu}_{t}^{n}\right)^{\prime}\left(V_{t}^{b}\right)^{-1}\left(r_{t+1}-\hat{\nu}_{t}^{n}\right)}, \\
R_{G L S, t}^{2}\left(V_{t}^{n}\right) & =1-\frac{\left(r_{t+1}-\hat{\alpha}_{t}-X_{t} \hat{\theta}_{t}\right)^{\prime}\left(V_{t}^{n}\right)^{-1}\left(r_{t+1}-\hat{\alpha}_{t}-X_{t} \hat{\theta}_{t}\right)}{\left(r_{t+1}-\hat{\nu}_{t}^{n}\right)^{\prime}\left(V_{t}^{n}\right)^{-1}\left(r_{t+1}-\hat{\nu}_{t}^{n}\right)}, \\
R_{G L S, t}^{2}\left(V_{t}^{b}, \hat{\Omega}_{t}^{n}\right) & =1-\frac{\left(r_{t+1}-\hat{\alpha}_{t}-X_{t} \hat{\theta}_{t}\right)^{\prime}\left(V_{t}^{b}\right)^{-1}\left(r_{t+1}-\hat{\alpha}_{t}-X_{t} \hat{\theta}_{t}\right)}{\left(r_{t+1}-\hat{\nu}_{t}^{n}\right)^{\prime}\left(V_{t}^{n}\right)^{-1}\left(r_{t+1}-\hat{\nu}_{t}^{n}\right)},
\end{aligned}
$$

where $V_{t}^{b}$ and $V_{t}^{n}$ are the variance matrices of the one-step prediction for the believer and the nonbeliever, respectively, used as weighting matrix here. Note that unlike welldefined in-sample $R^{2}$ s, there is no reason for the out-of-sample partial $R^{2}$ s to be definitely positive. If the prediction of the believer is worse than that of the nonbeliever, the outof-sample partial $R^{2}$ s can be negative. Table 8 reports the time-series averages of these quantities over the period 1971.01-1998.12.

\section{Table 8 here}

The numbers in Table 8 are revealing. In most cases, the out-of-sample partial $R^{2} \mathrm{~s}$ are negative, meaning that the believer actually predicts future returns more poorly than the nonbeliever using their own models. This happens when the model is poorly specified. Since the believer's model nests the nonbeliever's model and a linear function is the first-order approximation of any smooth functions, exploring other functional forms may not be a fruitful experiment. A more likely situation is that the relationship between the expected returns and the firm-specific variables is not stable over time. A recent study by Knez and Ready (1997), for example, documents that the size effect is caused by $1 \%$ of the data with extremely high returns and can be ruled out by a robust estimator. Another recent paper by Chen et al, (1998) shows that, even without outliers, $t$-ratios in cross-sectional regressions commonly used in empirical studies do not 
align with the economic significance of the return predictability. In any case, the lack of out-of-sample predictive power of the believer's model seems to be the culprit of the poor performance of the believer.

The result in Table 8 also has implications about another concern we mentioned earlier, the validity of the mean-variance analysis in measuring the true economic gains. Identifying the stochastic investment opportunity set is a difficult task, and implementing corresponding optimal investment strategies is probably more difficult. The difficulty makes it impossible to rule out the possibility that mean variance analysis is inappropriate. However, the result in Table 8 indicates that any deviation from mean variance analysis will most likely generate the same conclusion. This is so because the result in Table 8 is purely statistical. It does not depend on the specification of the utility function, the return distribution and the optimality of the believer's portfolio. Without being able to predict better, the believer cannot hope to gain over the nonbeliever.

\subsection{Simpler Strategies}

Given that model parameters are unstable and the optimality of the believer's portfolio is questionable, one might wonder if simpler strategies that do not rely on the exact weights of the optimal portfolios work. Lakonishok, Shleifer and Vishny (1994), for example, examine the issues using simple strategies. We perform similar analysis here as a robustness check. In our context, a natural way for the believer to follow is to add some simple zero-cost portfolios on the nonbeliever's optimal portfolio to generate returns as follows,

$$
r_{t+1}^{b}=r_{t+1}^{\prime} \xi_{t}^{n}+\phi_{1 t} \mathrm{SMB}_{t+1}+\phi_{2 t} \mathrm{HML}_{t+1}
$$

where SMB and HML are the Fama-French factor mimicking portfolio returns. Such strategies are simple in the sense that the believer simply takes the qualitative property that small and high book-to-market firms earn higher average returns than large and low book-to-market firms, without being concerned about exact optimal weights. From the 
returns on the portfolios of the nonbeliever and the believer, we calculate the differences in average returns and in certainty equivalents of expected utility. The results are in Table 9, expressed as dollar returns on a $\$ 100$ investment over a month. In Panel A of Table 9 the believer's portfolio simply takes $\phi_{1 t}=1$ and/or $\phi_{2 t}=1$, while in Panel $\mathrm{B}, \phi_{1 t}$ and $\phi_{2 t}$ are chosen to maximize the expected utility conditioned on the information at $t$. For example, when both SMB and HML portfolios are used, with $r_{F F, t+1}=\left(\mathrm{SMB}_{t+1}, \mathrm{HML}_{t+1}\right)^{\prime}$ and $\phi_{t}=\left(\phi_{1 t}, \phi_{2 t}\right)^{\prime}$,

$$
\begin{aligned}
\phi_{t}^{*} & =\arg \max _{\phi_{t}}-E_{t}\left[e^{-A\left(1+r_{0 t}+r_{t+1}^{\prime} \xi_{t}^{n}+\phi_{t}^{\prime} r_{F F, t+1}\right)}\right] \\
& =\arg \max _{\phi_{t}} E_{t}\left[\phi_{t}^{\prime} r_{F F, t+1}\right]-\frac{A}{2} \operatorname{Var}_{t}\left[r_{t+1}^{\prime} \xi_{t}^{n}+\phi_{t}^{\prime} r_{F F, t+1}\right] \\
& =\left[\operatorname{Var}_{t}\left(r_{F F, t+1}\right)\right]^{-1}\left(\frac{1}{A} E_{t}\left(r_{F F, t+1}\right)-\operatorname{Cov}_{t}\left(r_{F F, t+1}, r_{t+1}^{\prime} \xi_{t}^{n}\right)\right),
\end{aligned}
$$

where the conditional mean, variance and covariance are estimated using data up to $t$.

\section{Table 8 here}

From Panel A of Table 9, we can see that the difference in the expected returns between the believer and the nonbeliever is positive and, if HML is involved, it is also significant. This is hardly surprising because the difference is SMB and/or HML themselves. The differences in the certainty equivalents, however, are around zero and sometimes significantly negative. The increase in the variation cancels the gain in the expected returns. In Panel B, when the weights in the zero-cost portfolios are optimized, the gain in the certainty equivalents increases somewhat, but remains insignificant, while the mean returns are smaller than those in Panel A. Overall, we can conclude that the believer does not have significant gains in expected utility by using the two zero-cost portfolios. 


\section{Concluding Remarks}

In this paper, we address the issue of the return predictability by firm-specific variables documented in Fama and French (1992). We ask if return predictability has any normative implications. The question is answered by investigating whether an investor who forms mean-variance efficient portfolios conditioned on the predictive variables can earn higher expected return and higher expected utility.

The results show that return predictability does not generate economic gains. While the in-sample relation is strong in terms of $t$-statistics, it is not stable enough to produce better out-of-sample predictions. Even without estimation errors, the predictive power gives very little benefit for those who try to exploit it.

The results of this paper have implications for the debate on if return predictability is consistent with rational asset pricing theories. First, while return predictability from firm-specific variables remains a challenge to the CAPM, it does not provide solid grounds for arguing that the predictive power of the firm-specific variables is indicative of mis-pricing. There are no economic gains to be made from return predictability even within the mean-variance framework. Second, the economic significance of the return predictability is more relevant issue than the statistical significance measured by the $t$-ratios of the slope coefficients and the in-sample $R^{2}$ s of predictive regressions. They can be very different. Without economic gains, results from statistical significance are inconsequential. 


\section{References}

Chen, N., Kan, R. and Zhang, C., 1998, A critique of the use of $t$-ratios in model selection, Working paper.

Daniel, K. and Titman, S., 1997, Evidence on the characteristics of cross-sectional variation in stock returns, Journal of Finance, 52, 1-33.

Fama, E. and French, K., 1992, The cross-section of expected stock returns, Journal of Finance, 47, 427-465.

Fama, E. and French, K., 1993, Common risk factors in the returns on stocks and bonds, Journal of Financial Economics, 33, 3-56.

Fama, E. and French, K., 1996, Multifactor explanations of asset pricing anomalies, Journal of Finance, 51, 55-84.

Fama, E. and MacBeth, J., 1973, Risk, return and equilibrium: empirical tests, Journal of Political Economy 81, 607-636.

Ferson, W., 1996, Warning: attribute-sorted portfolios can be hazardous to your research, in Saitou, S., Sawaki, K. and Kubota, K. ed., Modern Portfolio Theory and Its Applications, Center for Academic Societies, Osaka, Japan.

Ferson, W., Sarkissian, S. and Simin, T., 1999, The alpha factor asset pricing model: a parable, Journal of Financial Markets 2, 49-68.

Kandel, S. and Stambaugh, R., 1996, On the predictability of stock returns: an assetallocation perspective, Journal of Finance, 52, 1996, 385-424.

Knez, P. and Ready, M., 1997, On the robustness of size and book-to-market in crosssectional regressions, Journal of Finance, 52, 1355-82. 
Lakonishok, J., Shleifer, A. and Vishny, R., 1994, Contrarian investment, extrapolation, and risk, Journal of Finance, 49, 1541-1578.

La Porta, R., Lakonishok, J., Shleifer, A. and Vishny, R., 1997, Good news for value stocks: further evidence on market efficiency, Journal of Finance, 52, 859-874.

MacKinlay, A.C., 1995, Multifactor models do not explain deviations from the CAPM, Journal of Financial Economics, 38, 3-28.

McCulloch, R. and Rossi, P., 1990, Posterior, predictive, and utility-based approaches to testing the arbitrage pricing theory, Journal of Financial Economics 28, 7-38.

Merton, R., 1973, An intertemporal asset pricing model, Econometrica, 41, 867-887.

Pesaran, M. H. and Timmermann, A., 1995, Predictability of stock returns: robustness and economic significance, Journal of Finance 50, 1201-1228. 
Table 1

Descriptive statistics for portfolio returns, sizes and book-to-market ratios

The table presents (A) time series means and standard deviations of portfolio returns, sizes and book-tomarket ratios for selected portfolios in eight sets of portfolios, (B) time series averages of cross sectional correlations between SZ and BM, and (C) the means and standard deviations of the Fama-French factors, SMB and HML. The time period is 1963.07-1998.12 unless otherwise indicated.

\begin{tabular}{|c|c|c|c|c|c|c|c|}
\hline \multicolumn{8}{|c|}{ A: Time series means and standard deviations of portfolio returns, sizes and book-to-market ratic } \\
\hline \multirow[t]{2}{*}{ Portfolio } & \multirow{2}{*}{$\begin{array}{c}\# \text { of firms } \\
\text { mean }\end{array}$} & \multicolumn{2}{|c|}{ returns $(\%)$} & \multicolumn{2}{|c|}{$\mathrm{SZ}$} & \multicolumn{2}{|c|}{$\mathrm{BM}$} \\
\hline & & mean & st.dev. & mean & st.dev. & mean & st.dev. \\
\hline \multicolumn{8}{|l|}{ SZ20 } \\
\hline 1 & 1210 & 1.204 & 6.803 & -3.425 & 0.495 & 0.290 & 0.170 \\
\hline 2 & 316 & 0.661 & 6.485 & -2.145 & 0.290 & 0.090 & 0.169 \\
\hline 3 & 215 & 0.685 & 6.374 & -1.759 & 0.187 & 0.079 & 0.121 \\
\hline 4 & 168 & 0.532 & 6.332 & -1.476 & 0.140 & 0.072 & 0.126 \\
\hline 5 & 143 & 0.796 & 6.172 & -1.214 & 0.100 & 0.076 & 0.126 \\
\hline 6 & 127 & 0.563 & 6.000 & -0.991 & 0.073 & 0.049 & 0.112 \\
\hline 7 & 113 & 0.663 & 5.870 & -0.776 & 0.063 & 0.061 & 0.110 \\
\hline 8 & 104 & 0.756 & 5.739 & -0.554 & 0.061 & -0.002 & 0.103 \\
\hline 9 & 97 & 0.707 & 5.645 & -0.348 & 0.060 & 0.027 & 0.147 \\
\hline 10 & 88 & 0.671 & 5.532 & -0.137 & 0.076 & -0.008 & 0.093 \\
\hline 11 & 81 & 0.557 & 5.355 & 0.064 & 0.091 & -0.015 & 0.082 \\
\hline 12 & 77 & 0.565 & 5.318 & 0.274 & 0.109 & -0.050 & 0.076 \\
\hline 13 & 73 & 0.590 & 5.252 & 0.499 & 0.103 & -0.033 & 0.081 \\
\hline 14 & 70 & 0.606 & 5.144 & 0.742 & 0.112 & -0.038 & 0.096 \\
\hline 15 & 69 & 0.536 & 4.967 & 0.984 & 0.114 & -0.030 & 0.119 \\
\hline 16 & 66 & 0.603 & 4.928 & 1.258 & 0.122 & -0.030 & 0.142 \\
\hline 17 & 63 & 0.571 & 4.811 & 1.530 & 0.132 & -0.028 & 0.150 \\
\hline 18 & 62 & 0.426 & 4.578 & 1.838 & 0.172 & -0.066 & 0.164 \\
\hline 19 & 61 & 0.499 & 4.541 & 2.296 & 0.194 & -0.105 & 0.166 \\
\hline 20 & 59 & 0.548 & 4.400 & 3.342 & 0.217 & -0.339 & 0.254 \\
\hline \multicolumn{8}{|l|}{ BM20 } \\
\hline 1 & 350 & 0.379 & 6.994 & 0.349 & 0.666 & -1.588 & 0.195 \\
\hline 2 & 199 & 0.533 & 6.480 & 0.443 & 0.364 & -0.927 & 0.119 \\
\hline 3 & 177 & 0.510 & 6.389 & 0.386 & 0.274 & -0.696 & 0.082 \\
\hline 4 & 164 & 0.547 & 6.260 & 0.368 & 0.257 & -0.529 & 0.057 \\
\hline 5 & 153 & 0.498 & 5.981 & 0.347 & 0.295 & -0.395 & 0.045 \\
\hline 6 & 152 & 0.645 & 5.863 & 0.244 & 0.198 & -0.291 & 0.048 \\
\hline 7 & 145 & 0.641 & 5.867 & 0.226 & 0.193 & -0.190 & 0.041 \\
\hline 8 & 135 & 0.643 & 5.520 & 0.302 & 0.227 & -0.108 & 0.042 \\
\hline 9 & 139 & 0.713 & 5.485 & 0.236 & 0.273 & -0.035 & 0.043 \\
\hline 10 & 137 & 0.665 & 5.279 & 0.229 & 0.196 & 0.027 & 0.042 \\
\hline 11 & 135 & 0.780 & 5.258 & 0.228 & 0.178 & 0.099 & 0.044 \\
\hline 12 & 135 & 0.856 & 5.208 & 0.150 & 0.181 & 0.159 & 0.045 \\
\hline 13 & 137 & 0.842 & 5.264 & 0.086 & 0.158 & 0.225 & 0.043 \\
\hline 14 & 131 & 0.953 & 5.286 & 0.082 & 0.296 & 0.289 & 0.047 \\
\hline 15 & 133 & 0.935 & 5.084 & -0.011 & 0.312 & 0.359 & 0.048 \\
\hline 16 & 138 & 0.968 & 5.396 & -0.227 & 0.303 & 0.438 & 0.049 \\
\hline 17 & 147 & 1.088 & 5.655 & -0.413 & 0.382 & 0.524 & 0.060 \\
\hline 18 & 158 & 1.179 & 5.689 & -0.639 & 0.274 & 0.633 & 0.070 \\
\hline 19 & 176 & 1.262 & 5.816 & -0.925 & 0.327 & 0.797 & 0.092 \\
\hline 20 & 220 & 1.401 & 6.237 & -1.462 & 0.317 & 1.210 & 0.151 \\
\hline
\end{tabular}


Table 1 (continued)

\begin{tabular}{|c|c|c|c|c|c|c|c|}
\hline \multirow{2}{*}{$\begin{array}{l}\text { Portfolio } \\
\text { SZBM25 }\end{array}$} & \multirow{2}{*}{$\begin{array}{c}\# \text { of firms } \\
\text { mean }\end{array}$} & \multicolumn{2}{|c|}{ returns (\%) } & \multicolumn{2}{|c|}{ SZ } & \multicolumn{2}{|c|}{$\mathrm{BM}$} \\
\hline & & mean & st.dev. & mean & st.dev. & mean & st.dev. \\
\hline 11 & 491 & 0.592 & 7.671 & -2.550 & 0.378 & -1.003 & 0.208 \\
\hline 12 & 309 & 0.860 & 6.852 & -2.583 & 0.318 & -0.198 & 0.077 \\
\hline 13 & 291 & 1.002 & 6.269 & -2.634 & 0.257 & 0.115 & 0.069 \\
\hline 14 & 316 & 1.051 & 5.996 & -2.679 & 0.306 & 0.380 & 0.063 \\
\hline 15 & 546 & 1.332 & 6.130 & -3.020 & 0.465 & 0.885 & 0.109 \\
\hline 21 & 137 & 0.486 & 7.259 & -0.751 & 0.098 & -0.973 & 0.140 \\
\hline 22 & 94 & 0.560 & 5.999 & -0.753 & 0.073 & -0.220 & 0.049 \\
\hline 23 & 91 & 0.688 & 5.409 & -0.730 & 0.077 & 0.081 & 0.048 \\
\hline 24 & 83 & 0.805 & 5.079 & -0.740 & 0.079 & 0.345 & 0.052 \\
\hline 25 & 68 & 1.010 & 5.615 & -0.767 & 0.088 & 0.807 & 0.092 \\
\hline 31 & 103 & 0.470 & 6.599 & 0.111 & 0.112 & -0.952 & 0.122 \\
\hline 32 & 71 & 0.518 & 5.407 & 0.116 & 0.080 & -0.241 & 0.043 \\
\hline 33 & 66 & 0.617 & 4.834 & 0.129 & 0.095 & 0.079 & 0.047 \\
\hline 34 & 57 & 0.783 & 4.823 & 0.127 & 0.101 & 0.344 & 0.050 \\
\hline 35 & 39 & 0.920 & 5.468 & 0.096 & 0.115 & 0.756 & 0.090 \\
\hline 41 & 79 & 0.486 & 5.768 & 1.021 & 0.124 & -0.967 & 0.139 \\
\hline 42 & 61 & 0.438 & 5.134 & 1.009 & 0.121 & -0.243 & 0.052 \\
\hline 43 & 53 & 0.574 & 4.842 & 1.027 & 0.137 & 0.075 & 0.061 \\
\hline 44 & 46 & 0.817 & 4.675 & 1.042 & 0.123 & 0.334 & 0.067 \\
\hline 45 & 29 & 0.953 & 5.422 & 1.010 & 0.165 & 0.744 & 0.091 \\
\hline 51 & 81 & 0.514 & 5.075 & 2.527 & 0.177 & -0.992 & 0.154 \\
\hline 52 & 52 & 0.452 & 4.692 & 2.284 & 0.231 & -0.258 & 0.068 \\
\hline 53 & 44 & 0.465 & 4.469 & 2.302 & 0.245 & 0.068 & 0.069 \\
\hline 54 & 36 & 0.574 & 4.364 & 2.249 & 0.216 & 0.329 & 0.071 \\
\hline 55 & 21 & 0.823 & 4.581 & 2.156 & 0.213 & 0.703 & 0.100 \\
\hline
\end{tabular}

B. Time series averages of cross-sectional correlations between SZ and BM

$\begin{array}{lcc}\text { Portfolio } & \text { mean } & \text { st.dev. } \\ \text { SZ20 } & -0.51 & 0.50 \\ \text { BM20 } & -0.66 & 0.27 \\ \text { SZBM25 } & -0.07 & 0.07\end{array}$

C. Time series means and standard deviations of Fama-French factors (1970.01-1998.12)

\begin{tabular}{lcc} 
Factor & mean & st.dev. \\
SMB & 0.19 & 3.06 \\
HML & 0.51 & 2.50 \\
\hline
\end{tabular}


Table 2

Fama-MacBeth regression results for portfolios

This table presents the Fama-MacBeth regression results for three sets of portfolios. The cross-sectional regression takes the form

$$
r_{t+1}=\theta_{0} 1_{N}+\theta_{1} \mathrm{SZ}_{t}+\theta_{2} \mathrm{BM}_{t}+\varepsilon_{t+1}
$$

for each month $t$, where $r_{t+1}$ is the excess return on $N$ portfolios, $\mathrm{SZ}_{t}$ is the size of $N$ portfolios and $\mathrm{BM}_{t}$ is the book-to-market of $N$ portfolios. The time series averages of the estimated parameters are reported with their time series standard errors in parentheses. The $R^{2}$ is the time series average of $R^{2}$ s for the cross-sectional regression of each month. The time period is $1963.07-1998.12$.

\begin{tabular}{|c|c|c|c|c|}
\hline Portfolio & $\theta_{0}$ & $\theta_{1}$ & $\theta_{2}$ & $R^{2}$ \\
\hline \multicolumn{5}{|l|}{$X_{t}=\mathrm{SZ}_{t}$} \\
\hline SZ20 & $\begin{array}{c}0.6415 \\
(0.2551)\end{array}$ & $\begin{array}{l}-0.0735 \\
(0.0437)\end{array}$ & & 0.3898 \\
\hline BM20 & $\begin{array}{c}0.8067 \\
(0.2696)\end{array}$ & $\begin{array}{l}-0.3185 \\
(0.0703)\end{array}$ & & 0.1996 \\
\hline SZBM25 & $\begin{array}{c}0.7164 \\
(0.2485)\end{array}$ & $\begin{array}{c}-0.0846 \\
(0.0440)\end{array}$ & & 0.2889 \\
\hline \multicolumn{5}{|l|}{$X_{t}=\mathrm{BM}_{t}$} \\
\hline SZ20 & $\begin{array}{c}0.6415 \\
(0.2551)\end{array}$ & & $\begin{array}{c}1.0054 \\
(0.2959)\end{array}$ & 0.2199 \\
\hline BM20 & $\begin{array}{c}0.8067 \\
(0.2696)\end{array}$ & & $\begin{array}{c}0.4079 \\
(0.0801)\end{array}$ & 0.3120 \\
\hline SZBM25 & $\begin{array}{c}0.7164 \\
(0.2485)\end{array}$ & & $\begin{array}{c}0.2786 \\
(0.0838)\end{array}$ & 0.1989 \\
\hline \multicolumn{5}{|c|}{$X_{t}=\left(\mathrm{SZ}_{t}, \mathrm{BM}_{t}\right)$} \\
\hline SZ20 & $\begin{array}{c}0.6415 \\
(0.2551)\end{array}$ & $\begin{array}{l}-0.0736 \\
(0.0504)\end{array}$ & $\begin{array}{c}0.3137 \\
(0.2111)\end{array}$ & 0.4547 \\
\hline BM20 & $\begin{array}{c}0.8067 \\
(0.2696)\end{array}$ & $\begin{array}{l}-0.2007 \\
(0.0847)\end{array}$ & $\begin{array}{c}0.1769 \\
(0.1007)\end{array}$ & 0.4223 \\
\hline SZBM25 & $\begin{array}{c}0.7164 \\
(0.2485)\end{array}$ & $\begin{array}{l}-0.0774 \\
(0.0444)\end{array}$ & $\begin{array}{c}0.2524 \\
(0.0845)\end{array}$ & 0.4906 \\
\hline
\end{tabular}


Table 3

Pooled regression results for portfolios

This table presents the final estimation results of the pooled time-series and crosssectional model for the three sets of portfolios. The regression takes the form

$$
r_{t+1}=\alpha+\theta_{1} \mathrm{SZ}_{t}+\theta_{2} \mathrm{BM}_{t}+\varepsilon_{t+1}
$$

where $r_{t+1}$ is the excess return on $N$ portfolios at $t+1, \mathrm{SZ}_{t}$ is the size of the $N$ portfolios, and $\mathrm{BM}_{t}$ is the book-to-market of the $N$ portfolios. The numbers in parentheses under $\theta$ estimates are their standard errors. $\chi_{2}^{2}(\theta=0)$ is the $\chi^{2}$-test for the hypothesis $\theta=0$ and $\chi_{N-1}^{2}\left(\alpha=\theta_{0} 1_{N}\right)$ is the $\chi^{2}$-test for the hypothesis $\alpha_{1}=\alpha_{2}=\cdots=\alpha_{N}$. The numbers in the brackets under the $\chi^{2}$-tests are their right-tail p-values. The time period is $1963.07-1998.12$.

\begin{tabular}{|c|c|c|c|c|}
\hline Portfolio & $\theta_{1}$ & $\theta_{2}$ & $\chi_{2}^{2}(\theta=0)$ & $\chi_{N-1}^{2}\left(\alpha=\theta_{0} 1_{N}\right)$ \\
\hline \multicolumn{5}{|l|}{$X_{t}=\mathrm{SZ}_{t}$} \\
\hline \multirow[t]{2}{*}{ SZ20 } & 0.143 & & 0.554 & 75.232 \\
\hline & $(0.193)$ & & {$[0.457]$} & {$[0.000]$} \\
\hline \multirow[t]{2}{*}{ BM20 } & -0.174 & & 8.732 & 24.218 \\
\hline & $(0.059)$ & & {$[0.003]$} & {$[0.188]$} \\
\hline \multirow[t]{2}{*}{ SZBM25 } & 0.017 & & 0.016 & 50.006 \\
\hline & $(0.131)$ & & {$[0.898]$} & {$[0.001]$} \\
\hline \multicolumn{5}{|c|}{$X_{t}=\mathrm{BM}_{t}$} \\
\hline \multirow[t]{2}{*}{ SZ20 } & & 0.156 & 1.444 & 75.744 \\
\hline & & $(0.130)$ & {$[0.230]$} & {$[0.000]$} \\
\hline \multirow[t]{2}{*}{ BM20 } & & 0.724 & 6.236 & 25.032 \\
\hline & & $(0.290)$ & {$[0.013]$} & {$[0.159]$} \\
\hline \multirow[t]{2}{*}{ SZBM25 } & & 0.485 & 4.899 & 33.743 \\
\hline & & $(0.219)$ & {$[0.027]$} & {$[0.089]$} \\
\hline \multicolumn{5}{|c|}{$X_{t}=\left(\mathrm{SZ}_{t}, \mathrm{BM}_{t}\right)$} \\
\hline \multirow[t]{2}{*}{ SZ20 } & 0.212 & 0.191 & 2.608 & 74.856 \\
\hline & $(0.198)$ & $(0.134)$ & {$[0.271]$} & {$[0.000]$} \\
\hline \multirow[t]{2}{*}{ BM20 } & -0.162 & 0.653 & 13.615 & 17.228 \\
\hline & $(0.059)$ & $(0.291)$ & {$[0.001]$} & {$[0.574]$} \\
\hline \multirow[t]{2}{*}{ SZBM25 } & 0.059 & 0.499 & 5.113 & 30.215 \\
\hline & $(0.132)$ & $(0.221)$ & {$[0.078]$} & {$[0.178]$} \\
\hline
\end{tabular}


Table 4

Difference in expected returns and certainty equivalents of expected utility.

This table reports time-series averages of the difference in the believer's portfolio return and the nonbeliever's portfolio return (column 2), the time series $t$-ratios of the difference in the two returns (column 3), the estimate of the difference in certainty equivalents for $A=2,5,8,12,15$ (columns 4-8) and their $t$-ratios (column 9). The numbers for the difference in returns (column 2) and difference in certainty equivalents (columns 4-8) are expressed as dollar returns on a $\$ 100$ investment over a month. The $t$-ratios (column 3 and 9) are calculated using the Newey-West adjustment with lag 3. The time period is 1971.01-1998.12.

\begin{tabular}{|c|c|c|c|c|c|c|c|c|}
\hline \multirow[t]{3}{*}{ Portfolios } & \multicolumn{2}{|c|}{ Diff. in returns } & \multicolumn{6}{|c|}{ Difference in certainty equivalents } \\
\hline & \multirow[t]{3}{*}{ mean } & \multirow[t]{2}{*}{$t$-ratio } & \multicolumn{5}{|c|}{ mean } & \multirow[t]{2}{*}{$t$-ratio } \\
\hline & & & $A=2$ & $A=5$ & $A=8$ & $A=12$ & $A=15$ & \\
\hline \multicolumn{8}{|l|}{$X_{t}=\mathrm{SZ}_{t}$} & \\
\hline SZ20 & 0.07 & 0.52 & -1.89 & -0.76 & -0.48 & -0.32 & -0.26 & -1.07 \\
\hline BM20 & 0.09 & 0.53 & -1.26 & -0.50 & -0.31 & -0.20 & -0.16 & -1.50 \\
\hline SZBM25 & -0.05 & -1.19 & -0.18 & -0.07 & -0.04 & -0.03 & -0.02 & -1.02 \\
\hline \multicolumn{9}{|l|}{$X_{t}=\mathrm{BM}_{t}$} \\
\hline SZ20 & -0.00 & -0.04 & -0.14 & -0.06 & -0.04 & -0.02 & -0.02 & -1.14 \\
\hline BM20 & 0.07 & 0.44 & -0.93 & -0.37 & -0.23 & -0.16 & -0.13 & -1.26 \\
\hline SZBM25 & 0.16 & 2.51 & 0.25 & 0.10 & 0.06 & 0.04 & 0.03 & 0.90 \\
\hline \multicolumn{9}{|c|}{$X_{t}=\left(\mathrm{SZ}_{t}, \mathrm{BM}_{t}\right)$} \\
\hline $\mathrm{SZ20}$ & 0.12 & 0.89 & -1.72 & -0.69 & -0.43 & -0.29 & -0.23 & -1.07 \\
\hline BM20 & 0.13 & 0.64 & -1.97 & -0.78 & -0.49 & -0.32 & -0.26 & -1.91 \\
\hline SZBM25 & 0.11 & 1.30 & 0.08 & 0.03 & 0.02 & 0.01 & 0.01 & 0.26 \\
\hline
\end{tabular}


Table 5

Variability of the believer's optimal portfolio weights.

This table presents the time series average, $D_{i},(i=a, b, c, d, e, f, g, h)$, of the following measures of variability of weights of the optimal portfolio of the believer for the three sets of portfolios,

$$
\begin{aligned}
D_{a, t} & =\frac{1}{N+1} \sum_{i=0}^{N}\left|\xi_{i t}^{b}-\xi_{i t}^{n}\right|, & D_{b, t} & =\frac{1}{N+1}\left(\sum_{i=0}^{N}\left(\xi_{i t}^{b}-\xi_{i t}^{n}\right)^{2}\right)^{1 / 2} \\
D_{c, t} & =\frac{\sum_{i=0}^{N}\left|\xi_{i t}^{b}-\xi_{i t}^{n}\right|}{\left.\sum_{i=0}^{N} \mid \xi_{i t}^{n}\right) \mid}, & D_{d, t} & =\left(\frac{\sum_{i=0}^{N}\left(\xi_{i t}^{b}-\xi_{i t}^{n}\right)^{2}}{\sum_{i=0}^{N}\left(\xi_{i t}^{n}\right)^{2}}\right)^{1 / 2} \\
D_{e, t} & =\frac{1}{N+1} \sum_{i=0}^{N}\left|\xi_{i t}^{b}-\xi_{i, t-1}^{b}\right|, & D_{f, t} & =\frac{1}{N+1}\left(\sum_{i=0}^{N}\left(\xi_{i t}^{b}-\xi_{i, t-1}^{b}\right)^{2}\right)^{1 / 2} \\
D_{g, t} & =\frac{\sum_{i=0}^{N}\left|\xi_{i t}^{b}-\xi_{i, t-1}^{b}\right|}{\sum_{i=0}^{N}\left|\xi_{i t}^{n}-\xi_{i, t-1}^{n}\right|}, & D_{h, t} & =\left(\frac{\sum_{i=0}^{N}\left(\xi_{i t}^{b}-\xi_{i, t-1}^{b}\right)^{2}}{\sum_{i=0}^{N}\left(\xi_{i t}^{n}-\xi_{i, t-1}^{n}\right)^{2}}\right)^{1 / 2} .
\end{aligned}
$$

$D_{a, t}, D_{b, t}, D_{e, t}$ and $D_{f, t}$ are proportional to the value of $1 / A$. The table reports those for $A=8$. The averages are taken for monthly data from 1971.01 to 1998.12.

\begin{tabular}{lcccccccc}
\hline Portfolios & $D_{a}$ & $D_{b}$ & $D_{c}$ & $D_{d}$ & $D_{e}$ & $D_{f}$ & $D_{g}$ & $D_{h}$ \\
$X_{t}=\mathrm{SZ}_{t}$ & & & & & & & & \\
$\mathrm{SZ20}$ & 0.196 & 0.055 & 0.203 & 0.207 & 0.044 & 0.012 & 1.366 & 1.379 \\
$\mathrm{BM} 20$ & 0.310 & 0.085 & 0.502 & 0.514 & 0.068 & 0.019 & 2.091 & 2.125 \\
$\mathrm{SZBM} 25$ & 0.067 & 0.018 & 0.107 & 0.113 & 0.037 & 0.009 & 1.130 & 1.151 \\
$X_{t}=\mathrm{BM}_{t}$ & & & & & & & & \\
$\mathrm{SZ20}_{\mathrm{BM} 20}$ & 0.058 & 0.016 & 0.062 & 0.061 & 0.049 & 0.014 & 1.538 & 1.568 \\
$\mathrm{SZBM}$ & 0.280 & 0.079 & 0.457 & 0.484 & 0.126 & 0.035 & 4.482 & 4.516 \\
$X_{t}=\left(\mathrm{SZ}_{t}, \mathrm{BM}_{t}\right)$ & & & & & & & & \\
$\mathrm{SZ20}_{\mathrm{BM} 20}$ & 0.231 & 0.064 & 0.240 & 0.242 & 0.057 & 0.016 & 1.913 & 1.938 \\
$\mathrm{SZBM}_{25}$ & 0.383 & 0.106 & 0.625 & 0.649 & 0.129 & 0.036 & 4.587 & 4.566 \\
\hline
\end{tabular}


Table 6

Percentiles of simulated time-series averages of the difference in returns and in the certainty equivalents.

The table reports 5\%, 25\%,50\%, $75 \%$ and $95 \%$ percentiles of four quantities, of 1000 replications of simulated, normally distributed returns based on the believer's recursively estimated parameters. The four quantities are time-series averages of the difference in the believer's portfolio return and nonbeliever's portfolio return (column 3), the time series $t$-ratios of the difference in the two returns (column 4), the estimate of the difference in certainty equivalents for $A=2,5,8,12,15$ (columns 5-9) and their $t$-ratios (column 10). The numbers for the difference in returns (column 2) and difference in certainty equivalents (columns 5-9) are expressed as dollar returns on a $\$ 100$ investment over a month. The $t$-ratios (column 4 and 10) are calculated using the Newey-West adjustment with lag 3. The time period is 1971.01-1998.12.

\begin{tabular}{|c|c|c|c|c|c|c|c|c|c|}
\hline \multirow[t]{3}{*}{ Portfolios } & & \multicolumn{2}{|c|}{ Diff. in returns } & \multicolumn{6}{|c|}{ Difference in certainty equivalents } \\
\hline & & \multirow[t]{3}{*}{ mean } & \multirow[t]{3}{*}{$t$-ratio } & \multicolumn{5}{|c|}{ mean } & \multirow[t]{2}{*}{$t$-ratio } \\
\hline & & & & $A=2$ & $A=5$ & $A=8$ & $A=12$ & $A=15$ & \\
\hline \multirow{6}{*}{$\begin{array}{l}X_{t}=\mathrm{SZ}_{t} \\
\mathrm{SZ20}\end{array}$} & & & & & & & & & \\
\hline & $5 \%$ & 0.19 & 1.67 & -0.21 & -0.08 & -0.05 & -0.03 & -0.03 & -0.46 \\
\hline & $25 \%$ & 0.29 & 2.68 & 0.23 & 0.09 & 0.06 & 0.04 & 0.03 & 0.48 \\
\hline & $50 \%$ & 0.36 & 3.30 & 0.55 & 0.22 & 0.14 & 0.09 & 0.07 & 1.22 \\
\hline & $75 \%$ & 0.43 & 3.90 & 0.86 & 0.34 & 0.21 & 0.14 & 0.11 & 1.91 \\
\hline & $95 \%$ & 0.54 & 4.83 & 1.31 & 0.52 & 0.33 & 0.22 & 0.17 & 2.99 \\
\hline \multirow[t]{5}{*}{ BM20 } & $5 \%$ & 0.20 & 1.55 & -0.14 & -0.05 & -0.03 & -0.02 & -0.02 & -0.23 \\
\hline & $25 \%$ & 0.32 & 2.46 & 0.41 & 0.16 & 0.10 & 0.07 & 0.05 & 0.76 \\
\hline & $50 \%$ & 0.40 & 3.10 & 0.78 & 0.31 & 0.19 & 0.13 & 0.10 & 1.44 \\
\hline & $75 \%$ & 0.48 & 3.79 & 1.16 & 0.46 & 0.29 & 0.19 & 0.15 & 2.17 \\
\hline & $95 \%$ & 0.60 & 4.72 & 1.64 & 0.65 & 0.41 & 0.27 & 0.22 & 3.20 \\
\hline \multirow[t]{5}{*}{ SZBM25 } & $5 \%$ & 0.00 & 0.05 & -0.21 & -0.08 & -0.05 & -0.03 & -0.03 & -1.23 \\
\hline & $25 \%$ & 0.04 & 1.02 & -0.04 & -0.02 & -0.01 & -0.01 & -0.01 & -0.27 \\
\hline & $50 \%$ & 0.06 & 1.62 & 0.06 & 0.03 & 0.02 & 0.01 & 0.01 & 0.39 \\
\hline & $75 \%$ & 0.09 & 2.35 & 0.18 & 0.07 & 0.05 & 0.03 & 0.02 & 1.11 \\
\hline & $95 \%$ & 0.12 & 3.33 & 0.33 & 0.13 & 0.08 & 0.05 & 0.04 & 2.12 \\
\hline
\end{tabular}


Table 6 (continued)

\begin{tabular}{|c|c|c|c|c|c|c|c|c|c|}
\hline \multirow[t]{3}{*}{ Portfolios } & & \multicolumn{2}{|c|}{ Diff. in returns } & \multicolumn{6}{|c|}{ Difference in certainty equivalents } \\
\hline & & \multirow[t]{2}{*}{ mean } & \multirow[t]{2}{*}{$t$-ratio } & \multicolumn{5}{|c|}{ mean } & \multirow[t]{2}{*}{$t$-ratio } \\
\hline & & & & $A=2$ & $A=5$ & $A=8$ & $A=12$ & $A=15$ & \\
\hline \multicolumn{10}{|l|}{$X_{t}=\mathrm{BM}_{t}$} \\
\hline \multirow[t]{5}{*}{ SZ20 } & $5 \%$ & -0.03 & -1.27 & -0.16 & -0.06 & -0.04 & -0.03 & -0.02 & -1.39 \\
\hline & $25 \%$ & -0.00 & -0.19 & -0.04 & -0.02 & -0.01 & -0.01 & -0.01 & -0.40 \\
\hline & $50 \%$ & 0.01 & 0.45 & 0.03 & 0.01 & 0.01 & 0.00 & 0.00 & 0.26 \\
\hline & $75 \%$ & 0.03 & 1.09 & 0.09 & 0.04 & 0.02 & 0.02 & 0.01 & 0.91 \\
\hline & $95 \%$ & 0.05 & 2.06 & 0.19 & 0.08 & 0.05 & 0.03 & 0.03 & 1.91 \\
\hline \multirow[t]{5}{*}{ BM20 } & $5 \%$ & 0.10 & 0.81 & -0.13 & -0.05 & -0.03 & -0.02 & -0.02 & -0.24 \\
\hline & $25 \%$ & 0.22 & 1.81 & 0.42 & 0.17 & 0.11 & 0.07 & 0.06 & 0.79 \\
\hline & $50 \%$ & 0.31 & 2.50 & 0.81 & 0.32 & 0.20 & 0.13 & 0.11 & 1.52 \\
\hline & $75 \%$ & 0.39 & 3.19 & 1.19 & 0.47 & 0.30 & 0.20 & 0.16 & 2.26 \\
\hline & $95 \%$ & 0.52 & 4.32 & 1.78 & 0.71 & 0.44 & 0.30 & 0.24 & 3.39 \\
\hline \multirow[t]{5}{*}{ SZBM25 } & $5 \%$ & 0.05 & 1.05 & -0.22 & -0.09 & -0.06 & -0.04 & -0.03 & -0.95 \\
\hline & $25 \%$ & 0.10 & 2.02 & -0.02 & -0.01 & -0.01 & -0.00 & -0.00 & -0.10 \\
\hline & $50 \%$ & 0.14 & 2.66 & 0.13 & 0.05 & 0.03 & 0.02 & 0.02 & 0.56 \\
\hline & $75 \%$ & 0.17 & 3.30 & 0.29 & 0.12 & 0.07 & 0.05 & 0.04 & 1.34 \\
\hline & $95 \%$ & 0.22 & 4.22 & 0.50 & 0.20 & 0.13 & 0.08 & 0.07 & 2.36 \\
\hline \multicolumn{10}{|c|}{$X_{t}=\left(\mathrm{SZ}_{t}, \mathrm{BM}_{t}\right)$} \\
\hline \multirow[t]{5}{*}{ SZ20 } & $5 \%$ & 0.19 & 1.64 & -0.24 & -0.10 & -0.06 & -0.04 & -0.03 & -0.46 \\
\hline & $25 \%$ & 0.31 & 2.70 & 0.26 & 0.10 & 0.06 & 0.04 & 0.03 & 0.54 \\
\hline & $50 \%$ & 0.39 & 3.37 & 0.62 & 0.25 & 0.15 & 0.10 & 0.08 & 1.29 \\
\hline & $75 \%$ & 0.47 & 3.96 & 1.00 & 0.40 & 0.25 & 0.16 & 0.13 & 2.05 \\
\hline & $95 \%$ & 0.58 & 4.82 & 1.42 & 0.57 & 0.35 & 0.24 & 0.19 & 2.98 \\
\hline \multirow[t]{5}{*}{ BM20 } & $5 \%$ & 0.35 & 2.14 & 0.21 & 0.08 & 0.05 & 0.03 & 0.03 & 0.32 \\
\hline & $25 \%$ & 0.49 & 3.04 & 0.85 & 0.34 & 0.21 & 0.14 & 0.11 & 1.20 \\
\hline & $50 \%$ & 0.60 & 3.70 & 1.38 & 0.55 & 0.34 & 0.23 & 0.18 & 1.99 \\
\hline & $75 \%$ & 0.71 & 4.39 & 1.88 & 0.75 & 0.47 & 0.31 & 0.25 & 2.68 \\
\hline & $95 \%$ & 0.85 & 5.48 & 2.51 & 1.00 & 0.63 & 0.42 & 0.33 & 3.70 \\
\hline \multirow[t]{5}{*}{ SZBM25 } & $5 \%$ & 0.09 & 1.52 & -0.27 & -0.11 & -0.07 & -0.05 & -0.04 & -0.92 \\
\hline & $25 \%$ & 0.15 & 2.43 & 0.02 & 0.01 & 0.01 & 0.00 & 0.00 & 0.07 \\
\hline & $50 \%$ & 0.19 & 3.09 & 0.20 & 0.08 & 0.05 & 0.03 & 0.03 & 0.73 \\
\hline & $75 \%$ & 0.23 & 3.73 & 0.40 & 0.16 & 0.10 & 0.07 & 0.05 & 1.48 \\
\hline & $95 \%$ & 0.29 & 4.76 & 0.65 & 0.26 & 0.16 & 0.11 & 0.09 & 2.54 \\
\hline
\end{tabular}


Table 7

Tests of parameter stability.

The left panel of the table reports results of Wald tests, likelihood-ratio (LR) tests and Lagrange multiplier (LM) tests of the hypothesis that $\left(\alpha, \theta_{1}, \theta_{2}\right)$ in the model

$$
r_{t+1}=\alpha+\theta_{1} \mathrm{SZ}_{t}+\theta_{2} \mathrm{BM}_{t}+\varepsilon_{t+1}
$$

remains the same for subperiods 1963.07-1981.03 and 1981.04-1998.12. The right panel of the table reports results of Wald tests, LR tests and LM tests of the hypothesis that $\left(\alpha, \theta_{1}, \theta_{2}\right)$ remains the same for subsamples of odd-months and even-months. The numbers in the brackets are the right-tail p-values.

\begin{tabular}{|c|c|c|c|c|c|c|}
\hline \multirow[t]{2}{*}{ Portfolios } & \multicolumn{3}{|c|}{ Before vs After } & \multicolumn{3}{|c|}{ Odd vs Even } \\
\hline & Wald & LR & LM & Wald & LR & LM \\
\hline \multicolumn{7}{|l|}{$X_{t}=\mathrm{SZ}_{t}$} \\
\hline \multirow[t]{2}{*}{ SZ20 } & 45.0544 & 43.0595 & 41.1773 & 32.5131 & 31.3102 & 30.1670 \\
\hline & {$[0.0017]$} & {$[0.0031]$} & {$[0.0053]$} & {$[0.0519]$} & {$[0.0686]$} & {$[0.0887]$} \\
\hline \multirow[t]{2}{*}{ BM20 } & 45.9992 & 44.0300 & 42.1663 & 46.2220 & 43.9952 & 41.9086 \\
\hline & {$[0.0013]$} & {$[0.0023]$} & {$[0.0040]$} & {$[0.0012]$} & {$[0.0023]$} & {$[0.0043]$} \\
\hline \multirow[t]{2}{*}{ SZBM25 } & 73.3556 & 67.7465 & 62.7010 & 51.4670 & 48.9146 & 46.5187 \\
\hline & {$[0.0000]$} & {$[0.0000]$} & {$[0.0001]$} & {$[0.0021]$} & {$[0.0042]$} & {$[0.0080]$} \\
\hline \multicolumn{7}{|l|}{$X_{t}=\mathrm{BM}_{t}$} \\
\hline \multirow[t]{2}{*}{ SZ20 } & 36.1525 & 34.6782 & 33.2845 & 31.3751 & 30.2733 & 29.2224 \\
\hline & {$[0.0210]$} & {$[0.0306]$} & {$[0.0432]$} & {$[0.0676]$} & {$[0.0866]$} & {$[0.1088]$} \\
\hline \multirow[t]{2}{*}{ BM20 } & 33.5150 & 32.0865 & 30.7487 & 45.2389 & 43.4891 & 41.8224 \\
\hline & {$[0.0408]$} & {$[0.0574]$} & {$[0.0779]$} & {$[0.0016]$} & {$[0.0027]$} & {$[0.0044]$} \\
\hline \multirow[t]{2}{*}{ SZBM25 } & 65.8118 & 61.4020 & 57.3727 & 42.8230 & 40.7798 & 38.8664 \\
\hline & {$[0.0000]$} & {$[0.0001]$} & {$[0.0004]$} & {$[0.0202]$} & {$[0.0327]$} & {$[0.0502]$} \\
\hline \multicolumn{7}{|c|}{$X_{t}=\left(\mathrm{SZ}_{t}, \mathrm{BM}_{t}\right)$} \\
\hline \multirow[t]{2}{*}{$\mathrm{SZ20}$} & 44.5495 & 42.5536 & 40.6735 & 32.6443 & 31.4317 & 30.2796 \\
\hline & {$[0.0030]$} & {$[0.0054]$} & {$[0.0090]$} & {$[0.0671]$} & {$[0.0876]$} & {$[0.1118]$} \\
\hline \multirow[t]{2}{*}{ BM20 } & 46.1595 & 44.1349 & 42.2240 & 56.3220 & 53.7211 & 51.2725 \\
\hline & {$[0.0019]$} & {$[0.0034]$} & {$[0.0059]$} & {$[0.0001]$} & {$[0.0002]$} & {$[0.0004]$} \\
\hline \multirow[t]{2}{*}{ SZBM25 } & 73.4625 & 68.0606 & 63.1796 & 52.0258 & 49.4063 & 46.9512 \\
\hline & {$[0.0000]$} & {$[0.0000]$} & {$[0.0001]$} & {$[0.0026]$} & {$[0.0053]$} & {$[0.0100]$} \\
\hline
\end{tabular}


Table 8

Time-series averages of one-step-ahead out-of-sample partial $R^{2}$.

The table reports time-series averages of out-of-sample partial $R^{2}$ s defined as follows. For each $t=1,2, \cdots, T-1$,

$$
\begin{aligned}
R_{O L S, t}^{2} & =1-\frac{\left(r_{t+1}-\hat{\alpha}_{t}-X_{t} \hat{\theta}_{t}\right)^{\prime}\left(r_{t+1}-\hat{\alpha}_{t}-X_{t} \hat{\theta}_{t}\right)}{\left(r_{t+1}-\hat{\nu}_{t}^{n}\right)^{\prime}\left(r_{t+1}-\hat{\nu}_{t}^{n}\right)} \\
R_{G L S, t}^{2}\left(V_{t}^{b}\right) & =1-\frac{\left(r_{t+1}-\hat{\alpha}_{t}-X_{t} \hat{\theta}_{t}\right)^{\prime}\left(V_{t}^{b}\right)^{-1}\left(r_{t+1}-\hat{\alpha}_{t}-X_{t} \hat{\theta}_{t}\right)}{\left(r_{t+1}-\hat{\nu}_{t}^{n}\right)^{\prime}\left(V_{t}^{b}\right)^{-1}\left(r_{t+1}-\hat{\nu}_{t}^{n}\right)} \\
R_{G L S, t}^{2}\left(V_{t}^{n}\right) & =1-\frac{\left(r_{t+1}-\hat{\alpha}_{t}-X_{t} \hat{\theta}_{t}\right)^{\prime}\left(V_{t}^{n}\right)^{-1}\left(r_{t+1}-\hat{\alpha}_{t}-X_{t} \hat{\theta}_{t}\right)}{\left(r_{t+1}-\hat{\nu}_{t}^{n}\right)^{\prime}\left(V_{t}^{n}\right)^{-1}\left(r_{t+1}-\hat{\nu}_{t}^{n}\right)} \\
R_{G L S, t}^{2}\left(V_{t}^{b}, V_{t}^{n}\right) & =1-\frac{\left(r_{t+1}-\hat{\alpha}_{t}-X_{t} \hat{\theta}_{t}\right)^{\prime}\left(V_{t}^{b}\right)^{-1}\left(r_{t+1}-\hat{\alpha}_{t}-X_{t} \hat{\theta}_{t}\right)}{\left(r_{t+1}-\hat{\nu}_{t}^{n}\right)^{\prime}\left(V_{t}^{n}\right)^{-1}\left(r_{t+1}-\hat{\nu}_{t}^{n}\right)}
\end{aligned}
$$

The differences arise from the weighting matrix being used. The time-series averages are taken for monthly data from 1971.01 to 1998.12 .

\begin{tabular}{lcccc}
\hline & $R_{O L S}^{2}$ & $R_{G L S}^{2}\left(\hat{V}_{t}^{b}\right)$ & $R_{G L S}^{2}\left(\hat{V}_{t}^{n}\right)$ & $R_{G L S}^{2}\left(\hat{V}_{t}^{b}, \hat{V}_{t}^{b}\right)$ \\
$X_{t}=\mathrm{SZ}_{t}$ & & & & \\
SE20 & -0.200 & -0.278 & -0.202 & -0.923 \\
BE20 & -0.306 & -0.099 & -0.316 & -0.955 \\
SBE25 & -0.093 & -0.078 & -0.094 & -0.840 \\
$X_{t}=\mathrm{BM}_{t}$ & & & & \\
SE20 & -0.002 & 0.028 & -0.002 & -0.613 \\
BE20 & -0.153 & 0.008 & -0.157 & -0.829 \\
SBE25 & 0.053 & 0.018 & 0.052 & -0.739 \\
$X_{t}=\left(\mathrm{SZ}_{t}, \mathrm{BM}_{t}\right)$ & & & & \\
SE20 & -0.200 & -0.235 & -0.199 & -0.968 \\
BE20 & -0.398 & -0.134 & -0.405 & -1.175 \\
SBE25 & -0.039 & -0.045 & -0.040 & -0.817 \\
\hline
\end{tabular}


Table 9

Results for simplified strategies.

The table reports time-series averages of the difference in the believer's portfolio return and nonbeliever's portfolio return, the time series $t$-ratios of the difference in the two returns, the estimate of the difference in certainty equivalents for $A=2,5,8,12,15$ and their $t$-ratios, where the believer uses simplified strategies of the form

$$
r_{t+1}^{b}=r_{t+1}^{\prime} \xi_{t}^{n}+\phi_{1 t} \mathrm{SMB}_{t+1}+\phi_{2 t} \mathrm{HML}_{t+1}
$$

where SMB is the return on the zero cost portfolio long in small firms and short in large firms and HML is the return on the zero cost portfolio long in high book-to-market firms and short in low book-to-market firms. The numbers are expressed as dollar returns for a $\$ 100$ investment over a month. The $t$-ratios in parentheses are calculated using the Newey-West adjustment with lag 3. The sample period is 1971.01-1998.12.

\begin{tabular}{|c|c|c|c|c|c|c|}
\hline & \multirow[t]{3}{*}{ Diff. in returns } & \multicolumn{5}{|c|}{ Difference in certainty equivalents } \\
\hline & & $A=2$ & $A=5$ & $A=8$ & $A=12$ & $A=15$ \\
\hline \multicolumn{6}{|c|}{ A: Simple strategies } & \\
\hline \multicolumn{7}{|c|}{$r_{t+1}^{n}=r_{0 t}+r_{t+1}^{\prime} \xi_{t}^{n}, \quad r_{t+1}^{b}=r_{t+1}^{n}+\mathrm{SMB}_{t+1}$} \\
\hline SZ20 & $\begin{array}{c}0.19 \\
(1.00)\end{array}$ & $\begin{array}{c}-0.19 \\
(-0.90)\end{array}$ & $\begin{array}{c}-0.32 \\
(-1.47)\end{array}$ & $\begin{array}{l}-0.45 \\
(-1.98)\end{array}$ & $\begin{array}{c}-0.61 \\
(-2.55)\end{array}$ & $\begin{array}{l}-0.73 \\
(-2.90)\end{array}$ \\
\hline BM20 & $\begin{array}{c}0.19 \\
(1.00)\end{array}$ & $\begin{array}{l}-0.07 \\
(-0.36)\end{array}$ & $\begin{array}{c}-0.21 \\
(-1.03)\end{array}$ & $\begin{array}{l}-0.34 \\
(-1.67)\end{array}$ & $\begin{array}{c}-0.51 \\
(-2.43)\end{array}$ & $\begin{array}{l}-0.63 \\
(-2.91)\end{array}$ \\
\hline SZBM25 & $\begin{array}{c}0.19 \\
(1.00)\end{array}$ & $\begin{array}{c}-0.03 \\
(-0.13)\end{array}$ & $\begin{array}{l}-0.15 \\
(-0.72)\end{array}$ & $\begin{array}{l}-0.27 \\
(-1.27)\end{array}$ & $\begin{array}{l}-0.43 \\
(-1.94)\end{array}$ & $\begin{array}{l}-0.55 \\
(-2.38)\end{array}$ \\
\hline \multicolumn{7}{|c|}{$r_{t+1}^{n}=r_{0 t}+r_{t+1}^{\prime} \xi_{t}^{n}, \quad r_{t+1}^{b}=r_{t+1}^{n}+\mathrm{HML}_{t+1}$} \\
\hline $\mathrm{SZ20}$ & $\begin{array}{c}0.51 \\
(3.29)\end{array}$ & $\begin{array}{c}0.40 \\
(2.20)\end{array}$ & $\begin{array}{c}0.29 \\
(1.57)\end{array}$ & $\begin{array}{l}0.18 \\
(0.94)\end{array}$ & $\begin{array}{c}0.03 \\
(0.14)\end{array}$ & $\begin{array}{l}-0.09 \\
(-0.38)\end{array}$ \\
\hline BM20 & $\begin{array}{c}0.51 \\
(3.29)\end{array}$ & $\begin{array}{l}-0.03 \\
(-0.17)\end{array}$ & $\begin{array}{c}-0.14 \\
(-0.67)\end{array}$ & $\begin{array}{l}-0.24 \\
(-1.11)\end{array}$ & $\begin{array}{c}-0.38 \\
(-1.62)\end{array}$ & $\begin{array}{l}-0.48 \\
(-1.92)\end{array}$ \\
\hline SZBM25 & $\begin{array}{c}0.51 \\
(3.29)\end{array}$ & $\begin{array}{c}-0.12 \\
(-0.57)\end{array}$ & $\begin{array}{c}-0.21 \\
(-0.98)\end{array}$ & $\begin{array}{l}-0.31 \\
(-1.35)\end{array}$ & $\begin{array}{l}-0.44 \\
(-1.75)\end{array}$ & $\begin{array}{l}-0.54 \\
(-1.98)\end{array}$ \\
\hline \multicolumn{7}{|c|}{$r_{t+1}^{n}=r_{0 t}+r_{t+1}^{\prime} \xi_{t}^{n}, \quad r_{t+1}^{b}=r_{t+1}^{n}+\mathrm{SMB}_{t+1}+\mathrm{HML}_{t+1}$} \\
\hline SZ20 & $\begin{array}{c}0.70 \\
(3.21)\end{array}$ & $\begin{array}{c}0.22 \\
(0.88)\end{array}$ & $\begin{array}{c}0.00 \\
(0.01)\end{array}$ & $\begin{array}{l}-0.22 \\
(-0.69)\end{array}$ & $\begin{array}{l}-0.53 \\
(-1.32)\end{array}$ & $\begin{array}{l}-0.78 \\
(-1.57)\end{array}$ \\
\hline BM20 & $\begin{array}{c}0.70 \\
(3.21)\end{array}$ & $\begin{array}{l}-0.10 \\
(-0.37)\end{array}$ & $\begin{array}{c}-0.32 \\
(-1.19)\end{array}$ & $\begin{array}{l}-0.54 \\
(-1.87)\end{array}$ & $\begin{array}{c}-0.84 \\
(-2.53)\end{array}$ & $\begin{array}{l}-1.06 \\
(-2.83)\end{array}$ \\
\hline SZBM25 & $\begin{array}{c}0.70 \\
(3.21)\end{array}$ & $\begin{array}{l}-0.12 \\
(-0.49)\end{array}$ & $\begin{array}{c}-0.30 \\
(-1.18)\end{array}$ & $\begin{array}{l}-0.49 \\
(-1.76)\end{array}$ & $\begin{array}{c}-0.75 \\
(-2.35)\end{array}$ & $\begin{array}{c}-0.94 \\
(-2.65)\end{array}$ \\
\hline
\end{tabular}


Table 9 (continued)

\begin{tabular}{|c|c|c|c|c|c|c|}
\hline & \multirow{2}{*}{$\frac{\text { Diff. in returns }}{A=8}$} & \multicolumn{5}{|c|}{ Difference in certainty equivalents } \\
\hline & & $A=2$ & $A=5$ & $A=8$ & $A=12$ & $A=15$ \\
\hline \multicolumn{7}{|c|}{ B: Optimal strategies } \\
\hline \multicolumn{7}{|c|}{$r_{t+1}^{n}=r_{0 t}+r_{t+1}^{\prime} \xi_{t}^{n}, \quad r_{t+1}^{b}=r_{t+1}^{n}+\phi_{1 t}^{*} \mathrm{SMB}_{t+1}$} \\
\hline SZ20 & $\begin{array}{c}-0.02 \\
(-2.01)\end{array}$ & $\begin{array}{c}-0.02 \\
(-0.47)\end{array}$ & $\begin{array}{c}-0.01 \\
(-0.47)\end{array}$ & $\begin{array}{c}-0.01 \\
(-0.48)\end{array}$ & $\begin{array}{c}-0.00 \\
(-0.49)\end{array}$ & $\begin{array}{c}-0.00 \\
(-0.49)\end{array}$ \\
\hline BM20 & $\begin{array}{l}-0.01 \\
(-0.34)\end{array}$ & $\begin{array}{c}0.02 \\
(0.19)\end{array}$ & $\begin{array}{c}0.01 \\
(0.19)\end{array}$ & $\begin{array}{c}0.01 \\
(0.18)\end{array}$ & $\begin{array}{c}0.00 \\
(0.18)\end{array}$ & $\begin{array}{c}0.00 \\
(0.18)\end{array}$ \\
\hline SZBM25 & $\begin{array}{c}0.00 \\
(0.82)\end{array}$ & $\begin{array}{c}0.01 \\
(0.33)\end{array}$ & $\begin{array}{c}0.00 \\
(0.33)\end{array}$ & $\begin{array}{c}0.00 \\
(0.33)\end{array}$ & $\begin{array}{c}0.00 \\
(0.33)\end{array}$ & $\begin{array}{c}0.00 \\
(0.33)\end{array}$ \\
\hline \multicolumn{7}{|c|}{$r_{t+1}^{n}=r_{0 t}+r_{t+1}^{\prime} \xi_{t}^{n}, \quad r_{t+1}^{b}=r_{t+1}^{n}+\phi_{2 t}^{*} \mathrm{HML}_{t+1}$} \\
\hline SZ20 & $\begin{array}{c}0.43 \\
(3.13)\end{array}$ & $\begin{array}{c}0.49 \\
(0.62)\end{array}$ & $\begin{array}{c}0.19 \\
(0.62)\end{array}$ & $\begin{array}{c}0.12 \\
(0.62)\end{array}$ & $\begin{array}{c}0.08 \\
(0.62)\end{array}$ & $\begin{array}{c}0.06 \\
(0.62)\end{array}$ \\
\hline BM20 & $\begin{array}{l}-0.00 \\
(-0.16)\end{array}$ & $\begin{array}{l}-0.05 \\
(-0.65)\end{array}$ & $\begin{array}{l}-0.02 \\
(-0.65)\end{array}$ & $\begin{array}{l}-0.01 \\
(-0.65)\end{array}$ & $\begin{array}{l}-0.01 \\
(-0.65)\end{array}$ & $\begin{array}{c}-0.01 \\
(-0.65)\end{array}$ \\
\hline SZBM25 & $\begin{array}{c}0.00 \\
(0.54)\end{array}$ & $\begin{array}{c}0.02 \\
(0.61)\end{array}$ & $\begin{array}{c}0.01 \\
(0.61)\end{array}$ & $\begin{array}{c}0.01 \\
(0.60)\end{array}$ & $\begin{array}{c}0.00 \\
(0.60)\end{array}$ & $\begin{array}{c}0.00 \\
(0.60)\end{array}$ \\
\hline \multicolumn{7}{|c|}{$r_{t+1}^{n}=r_{0 t}+r_{t+1}^{\prime} \xi_{t}^{n}, \quad r_{t+1}^{b}=r_{t+1}^{n}+\phi_{1 t}^{*} \mathrm{SMB}_{t+1}+\phi_{2 t}^{*} \mathrm{HML}_{t+1}$} \\
\hline SZ20 & $\begin{array}{c}0.40 \\
(2.86)\end{array}$ & $\begin{array}{c}0.35 \\
(0.45)\end{array}$ & $\begin{array}{c}0.14 \\
(0.45)\end{array}$ & $\begin{array}{c}0.09 \\
(0.45)\end{array}$ & $\begin{array}{c}0.06 \\
(0.45)\end{array}$ & $\begin{array}{c}0.05 \\
(0.44)\end{array}$ \\
\hline BM20 & $\begin{array}{l}-0.02 \\
(-0.58)\end{array}$ & $\begin{array}{c}-0.04 \\
(-0.28)\end{array}$ & $\begin{array}{l}-0.02 \\
(-0.28)\end{array}$ & $\begin{array}{l}-0.01 \\
(-0.28)\end{array}$ & $\begin{array}{l}-0.01 \\
(-0.28)\end{array}$ & $\begin{array}{c}-0.01 \\
(-0.28)\end{array}$ \\
\hline SZBM25 & $\begin{array}{c}0.01 \\
(1.04)\end{array}$ & $\begin{array}{c}0.03 \\
(0.64)\end{array}$ & $\begin{array}{c}0.01 \\
(0.64)\end{array}$ & $\begin{array}{c}0.01 \\
(0.63)\end{array}$ & $\begin{array}{c}0.01 \\
(0.63)\end{array}$ & $\begin{array}{c}0.00 \\
(0.63)\end{array}$ \\
\hline
\end{tabular}

